\title{
Espacio social y áreas de actividad en asentamientos agrícolas prehispánicos tardíos en la sierra de Arica
}

Espace social et zones d'activité sur des sites agricoles préhispaniques récents de la sierra de Arica

Social space and activity area in late Prehispanic agricultural sites in the

highlands of Arica

Iván Muñoz Ovalle

\section{(2) OpenEdition}

\section{Journals}

Edición electrónica

URL: http://journals.openedition.org/bifea/4880

DOI: $10.4000 /$ bifea. 4880

ISSN: 2076-5827

Editor

Institut Français d'Études Andines

Edición impresa

Fecha de publicación: 1 diciembre 2005

Paginación: 321-355

ISSN: 0303-7495

Referencia electrónica

Iván Muñoz Ovalle, «Espacio social y áreas de actividad en asentamientos agrícolas prehispánicos tardíos en la sierra de Arica », Bulletin de l'Institut français d'études andines [En línea], 34 (3) | 2005,

Publicado el 08 diciembre 2005, consultado el 01 diciembre 2020. URL : http:// journals.openedition.org/bifea/4880; DOI : https://doi.org/10.4000/bifea.4880

\section{(9) $(0 \Theta \Theta$}

Les contenus du Bulletin de l'Institut français d'études andines sont mis à disposition selon les termes de la licence Creative Commons Attribution - Pas d'Utilisation Commerciale - Pas de Modification 4.0 International. 


\title{
Espacio social y áreas de actividad en asentamientos agrícolas prehispánicos tardíos en la sierra de Arica*
}

\author{
Iván Muñoz Ovalle**
}

\begin{abstract}
Resumen
El presente trabajo tiene como objetivo discutir el espacio social generado en tres de los mayores asentamientos prehispánicos ubicados en la sierra de Arica, sobre los $3000 \mathrm{msnm}$, extremo norte de Chile: Huaihuarani, Lupica y Saxamar. La discusión está centrada en el análisis de una serie de áreas de actividad que se generaron tanto al interior de los recintos habitacionales como fuera de ellos, así como: terrazas de cultivos, caminos, plazas, corrales, enterramiento, pozos de almacenajes y los componentes cerámicos que aparecen distribuidos en dichas áreas. Este conjunto de evidencias ha permitido estructurar el comportamiento de las sociedades prehispánicas tardías (1000 al 1500 d. C.), en la perspectiva económica y social, de una población adaptada a un medio de desierto marginal de altura.
\end{abstract}

Palabras clave - espacio social, áreas de actividad, asentamientos prehispánicos

\section{Espace social et zones d'activité sur des sites agricoles préhispaniques récents de la sierra de Arica}

\section{Résumé}

Cette étude se propose d'examiner l'espace social des trois des plus grands sites préhispaniques situés dans la sierra d'Arica, à 3000 m d'altitude, à l' extrême nord du Chili : Huaihuarani, Lupica y Saxamar. La discussion tourne autour de l'analyse d'une série de secteurs d'activité tant à l'intérieur qu'à l'extérieur des enceintes d'habitat : les terrasses agricoles, les chemins, les places, les enceintes, les enterrements, les stocks de vivres et le matériel céramique répartis dans ces secteurs, par exemple.

* Este artículo es resultado del proyecto Fondecyt 1040296.

** Académico del Departamento de Antropología, Universidad de Tarapacá, Arica, Chile. E-mail: imunoz@uta.cl 
Cet ensemble d'éléments nous a permis de structurer le comportement des sociétés préhispaniques récentes (1000 à 1600 d.C), sur le plan économique et social, pour une société andine adaptée à un milieu désertique marginal d'altitude.

Mots clés - espace social, zones d'activité, établissements préhispaniques

\title{
Social space and activity area in late Prehispanic agricultural sites in the highlands of Arica
}

\begin{abstract}
The objective of the present essay is to discuss the social space generated in three of the biggest prehispanic sites placed in the highland of Arica, located at over 3000 m.asl. in the northern extreme of Chile: Huaihuarani, Lupica and Saxamar.. The discussion is focused on a group of activity areas generated not only inside domestic areas but also outside of them, such crop terraces, raods, plazas corrals, burials, and storage pits. This study also considers the distribution pottery in the areas. This evidence has allowed us to identify from an economic and social perspective the structure the behaviour of late Prehispanic societies (AD 1000 to 1500) of a population which is adapted to a background placed in the desert of highlands.
\end{abstract}

Key words - Social space, area of activity, settlement Prehispanic

\section{EL PROBLEMA DE ESTUDIO}

La investigación arqueológica en los valles de Arica ha reconstruido la prehistoria regional a través del estudio fundamentalmente de cementerios, abordando temáticas específicas relacionadas con análisis de cerámica, textiles, maderas, osamentas, etc. Tal es así que, para el valle de Azapa, se ha planteado una larga secuencia cultural de más de 9000 años enfatizando aspectos relacionados con los rituales de la muerte. A diferencia de estas investigaciones de carácter funerario, denotamos un número reducido de investigaciones sobre patrones habitacionales relacionadas a la reconstrucción del espacio social y las economías de subsistencia. Por tal razón, el tema a investigar adquiere importancia en la medida que se dispondrá de información para inferir aspectos relacionados con la vida cotidiana de las poblaciones que se asentaron en la sierra de Arica, durante los períodos Intermedio Tardío (1100 d. C.) y Tardío (1500 d. C.).

Para enfrentar esta investigación hemos elegido las quebradas serranas de Lupica, Belén y Ticnamar, espacios geográficos donde se hallan los asentamientos de Huaihuarani, Lupica y Saxamar, constituyéndose en los más representativos de los períodos Intermedio Tardío y Tardío 


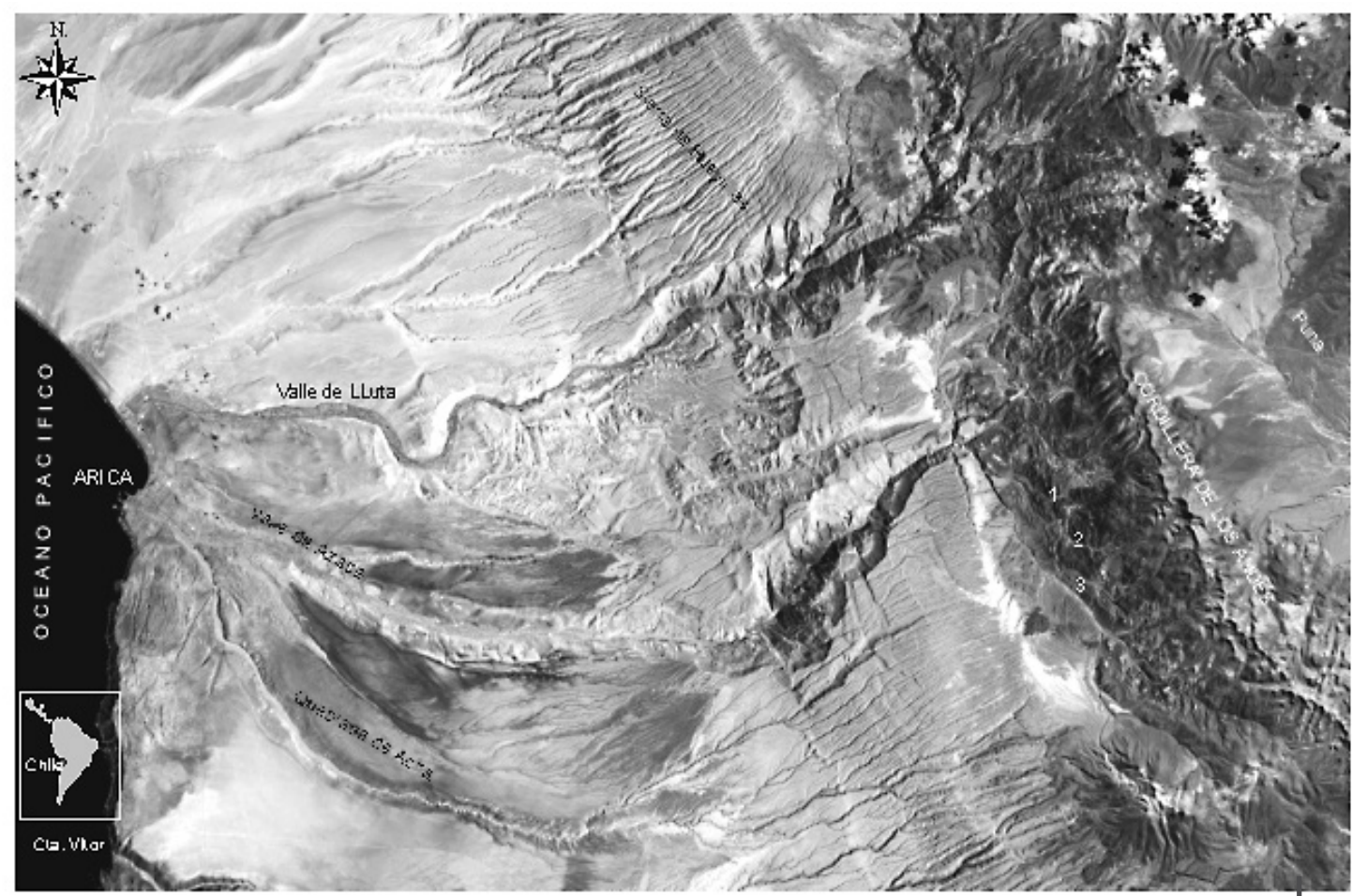

Figura 1 - Imagen digital de ubicación de sitios en la sierra de Arica, Extremo norte de Chile 1. Huaihuarane Belén; 2. Lupica, valle de Lupica; 3. Saxamar, valle del río Tignamar Fuente: NASA, cuadrante S-19-15; Escala 1:628:010:696

ubicados sobre los 3000 msnm; cada uno presentando ellos edificaciones de piedra y materiales vinculados a las actividades domésticas distribuidos en su superficie (fig. 1). Al parecer fueron sitios estratégicos vinculados a la interacción social y económica durante los períodos tardíos de la prehistoria andina, especialmente entre poblaciones costeras vinculadas a la Cultura Arica y las pertenecientes a los reinos altiplánicos postiwanaku.

Sobre las áreas de actividad, su estudio proporcionará información en torno a cómo se articuló el espacio doméstico al interior y exterior de las viviendas que conformaron los asentamientos antes mencionados. Permitirá abordar las diferencias y similitudes de los espacios, las interrelaciones humanas que se dieron en ellos, las actividades que se expresaron y los objetos que se utilizaron en el desarrollo de la vida cotidiana.

Para abordar el estudio se propuso obtener la información de terreno a través de una prospección y excavación de pozos de sondeo de $800 \mathrm{~m}^{2}$ por asentamiento. En cada asentamiento se excavó un $0,25 \%$, lo que en número fueron más de 12 estructuras por asentamiento. Cada uno de estos espacios corresponde aproximadamente a un $10 \%$ de los componentes estructurales del poblado. De tal manera que la información obtenida nos permitió describir distintas evidencias de lo que fue la vida doméstica en cada uno de los asentamientos.

A partir de la problemática descrita nuestra hipótesis plantea que las áreas domésticas en los asentamientos de Huiahuarani, Lupica y Saxamar son testimonios de las actividades económicas y sociales generadas por los grupos humanos que se asentaron en cada uno de estos poblados como asimismo, de las relaciones que pudieron establecer estos, con otros grupos del valle, en 
el contexto de las relaciones de reciprocidad e intercambio. Estas poblaciones participaron de una red de influencias y contactos marcada al parecer por la organización política que ejerció en los valles serranos la Cultura Arica junto a las poblaciones dependientes de los reinos altiplánicos postiwanaku. Sin embargo, la esencia de este proceso se fundamenta en el sentido que las relaciones de reciprocidad establecidas entre los individuos sumadas a la complementariedad de recursos habría permitido el desarrollo y crecimiento de la población de los valles de Lupica, Belén y Saxamar.

Teniendo presente lo anteriormente planteado, el objetivo del trabajo apunta a reconstruir el espacio social de las poblaciones Huaihuarani, Lupica y Saxamar, con el propósito de conocer el modo de vida de los agricultores de la sierra de Arica. Para alcanzar dicho objetivo estudiamos la arquitectura habitacional para entender aspectos constructivos, distribución, acceso, dimensión de los recintos, orientación, etc. para inferir la naturaleza del grupo doméstico que habitó dichos espacios; describiremos los componentes culturales de las áreas de actividad doméstica y la cerámica, información fundamental para la identificación de los grupos que ocuparon dichos espacios. Ambos estudios permitirán identificar el tipo de actividades que se llevaron a cabo en los espacios domésticos, inferir sus funciones y las posibles relaciones sociales establecidas en ellos.

\section{ANTECEDENTES SOBRE LOS ESTUDIOS DE ASENTAMIENTO}

Estos han tenido un desarrollo gradual en lo que se refiere a enfoques y procedimientos en los valles del extremo norte de Chile y sur del Perú, desde una etapa descriptiva en que se remarca las evidencias culturales halladas en los recintos que conforman los asentamientos, pasando por estudios interdisciplinarios en que se enfatizan aspectos espaciales, económicos, nutricionales, arquitectónicos, hasta llegar a la actualidad con estudios más complejos como son los sistemas agrícolas (riego, campos de cultivo), incluido el paleoambiente (Rivera et al., 1995-1996). Sin embargo, a pesar de este enfoque multidisciplinario, es necesario estudiar aspectos que analicen el grado de especialización del trabajo familiar, preparación y consumo de alimentos y la actividad social que se pudo generar en los espacios domésticos.

En los valles altos de Arica y Tacna los estudios de asentamientos se han enfocado principalmente a analizar: a) características físicas y arquitectónicas de los poblados, b) el tiempo de permanencia de éstos y, c) la ubicación espacial de los poblados y su relación con la ecología del lugar. Todo esto con el propósito de plantear correlaciones con otros asentamientos y discutir sobre la organización social y económica de los grupos asentados (Niemeyer et al., 1971; Niemeyer \& Schiappacasse, 1981; Dauelsberg, 1983; Santoro et al., 1987; Santoro, 1995; Romero, 2003; Schiappacasse \& Niemeyer, 1998; Muñoz et al., 1997; Gordillo, 1996).

Más al sur, específicamente en el valle de Tarapacá, el estudio del asentamiento de Caserones ha proporcionado una interesante información respecto a «[...] cualificar y cuantificar el temprano hábitat agrario semiurbano» en el curso inferior de la quebrada de Tarapacá (Nuñez, 1982: 80). Si bien hay un esquema de periodificación, donde se resalta el desarrollo evolutivo del poblado (períodos I al IV), se enfatiza en las áreas de actividad y en las estrategias organizativas de la población conllevando al surgimiento de autoridad y especialización de oficios. Al analizar la producción de alimentos se identificaron especies tanto vegetales como animales, lo cual le permitió a Núñez hacer un planteamiento de naturaleza paleonutricional en relación a los grupos que ocuparon dicho poblado.

Para el extremo sur del Perú, Aldenderfer (1990) presenta asentamientos de cazadores y recolectores en el sitio Asana Moquegua; propone siete estilos arquitectónicos caracterizando distintos niveles de ocupación, relacionados con las fases arcaicas. La arquitectura residencial se caracteriza por estructuras circulares donde se distribuyen una serie de componentes domésticos como manchones de cenizas, carbones, fogones, postes de maderas y sectores de basuras diseminados fuera y dentro de los espacios habitacionales. En el mismo valle, pero para el período Medio, Goldstein (1989), en base a tecnología computacional y fotografía aérea, ha 
estudiado la arquitectura doméstica y ceremonial del asentamiento Omo para definir el tipo de patrón de asentamiento provincial de carácter administrativo vinculado al sitio epónimo de Tiwanaku. Señala que este estuvo constituido por una estructura pública construida por plataformas escalonadas con paredes de adobe y una fachada principal de piedra tallada donde se practicaron sacrificios de camélidos, ofrendando con tiestos de cerámica. Añade que en estas ceremonias se usaron sahumerios. También se han realizado estudios sobre sistemas agrícolas (andenerías y canales) y unidades habitacionales con el propósito de conocer las economías agrarias postiwanaku (Stanish, 1990). Este último estudio se inserta dentro del análisis de la complementariedad económica en la prehistoria tardía de la cuenca de Osmore.

En el valle de Otara Moquegua, Stanish (1990) al referirse a la complementariedad zonal señala sitios con diversas características estratégicas. Por ejemplo Cuajone o P-8 estaba constituido por extensos campos aterrazados donde se levantaron una serie de recintos; este sitio caracteriza al período Otara. Los sitios de este período son abiertos, ubicados sobre lomas y cerros, no presentan una posición defensiva. En el período Tumilaca los sitios conservan la misma estructura que Otara como lo demuestra P-5, es decir, construcciones en laderas abiertas sin una posición defensiva. La diferencia se observa en el período Estuquiña en los sitios P-1, P-2 y P-3 donde los sitios presentan estructuras de fortalezas.

Williams et al. (2001: 75), al analizar el asentamiento de Cerro Baúl como enclave Wari en el valle de Moquegua, señalan que uno de los rasgos arquitectónicos más importantes son los recintos vecinales, que sirvieron para albergar familias, en otras ocasiones para el trabajo de la comunidad, y para almacenar productos. Una de las estructuras más importante, en forma de $\mathrm{D}$, fue destinada para cumplir funciones ceremoniales donde practicaron sacrificios y veneraron a los dioses.

En el área nuclear de Tiwanaku, circumtiticaca, Kolata (1989) señala que asentamientos como Lukurmata, Pajchiri, Aje, reflejan el patrón organizativo de un estado urbano o de grupos poblacionales organizados, localizados en planices lacustres, óptimas para la agricultura. Al referirse al sistema de asentamientos de Lukurmata, uno de los dos más grandes asentamientos en el área de Tiwanaku, plantea que en este complejo urbanístico se construyeron dos tipos de estructuras domésticas. Las primeras se caracterizan por sólidas residencias con cimientos de piedras, pisos gruesos de arcilla y paredes de adobe, que al parecer estuvieron asociadas a grupos de élite. Las segundas estructuras de forma oval o rectangular se asocian a la producción textil especializada o a la confección de instrumentos de piedras. Estas estructuras se ubican en el período Tiwanaku III ubicadas en terrazas artificiales. Estos dos tipos de estructuras se ubican entre la época III y IV.

Kolata (1989: 28) determinó cinco zonas distintas de cultivos y sitios de ocupación. En primer lugar, una necrópolis pública monumental de piedra. En segundo lugar, residencias domésticas de la clase élite, concentrando la producción artesanal de textiles y utensilios de piedras. En tercer lugar, un área de residuos domésticos de élite (Clase I). En cuarto lugar, un sector de terrazas residenciales domésticas conformadas por bases circulares (Clase III). Y en quinto lugar, una franja agrícola de cultivos locales de construcción elaborada y canales.

Stanish (1989:42) señala que Lukurmata no solamente fue un centro urbano nuclear sino que además había una población no elitista más amplia localizada en la periferia, diseminada dentro de un extenso y relativamente homogéneo asentamiento. Bermann \& Graffman (1989) describen la arquitectura residencial del período Tiwanaku en Lukurmata de los períodos III (200-500 d. C.) y IV (500-900 d. C.). Al comparar los recintos 2 y 7 observan diferencias entre ellas, diferenciándose en el plano y en los rasgos internos. En el recinto 2 se hallaron 3 fogones, lo que corresponde a una estructura de forma oblonga irregular con un tamaño de $2 \times 4 \mathrm{~m}$ con un poste central. El recinto 7 es una estructura circular con diámetro de $3 \mathrm{~m}$ donde se halló un solo fogón.

Albarracín \& Mathews (1990: 140), al referirse al patrón de asentamiento del período Pacajes Temprano (1100-1470 d. C.), señalan que la característica más importante es la proliferación 
de sitios pequeños no mostrando una configuración ordenada en la red de asentamientos como consecuencia del proceso de fragmentación de Tiwanaku en el período $\mathrm{V}$, presentando extensiones menores a una hectárea.

Janusek (2001: 257) señala que en buena parte del asentamiento de Tiwanaku se llevaron a cabo actividades no relacionadas con la vida doméstica, que los lugares donde la gente dormía, se alimentaba y educaba a los niños solían ser los mismos sitios donde se llevaban a cabo las ceremonias cíclicas o donde se efectuaban los negocios particulares. Que Tiwanaku fue un sitio dinámico donde la vida doméstica estuvo cada vez más ligada a una gran convergencia social y ceremonial. En Akapana Este 1 y 2 la actividad doméstica se registra en las basuras dejadas en los patios externos, los que conforman los focos principales de la vida doméstica y social cotidiana que ejecutaron los componentes de las unidades domésticas. Allí se prepararon y consumieron los alimentos, desollaron pieles, guardaron alimentos secos y líquidos en recipientes. Las actividades de cocina están documentada en fogones, combustible, hornos, ollas y tinajas. Dentro de la actividad doméstica ceremonial se hallaron implementos de hueso y piedra, sahumadores hechos en cerámica, entierros de fetos de camélidos y entierros humanos depositados en los pisos y muros de las áreas residenciales. Fueron halladas una variedad de vasijas que al parecer correspondieron a bienes de estatus social y de identidad dentro del marco de las fiestas cíclicas.

Nielsen \& Rivolta (1997) señalan que en el período tardío en las estructuras residenciales de la quebrada de Humahuaca, noreste argentino, una característica recurrente de los yacimientos con ocupación doméstica breve es su baja concentración de material de basuras y desechos artefactuales, además de una escasa relación entre estructuras, ausencia de vías de circulación y estructuras techadas. A diferencia de estas, los sitios de ocupación prolongada ostentan un trazado denso con grandes estructuras, y espacios abiertos y sectores densamente poblados, hay una gran cantidad de estructuras de tamaño reducido, con modificación y reocupadas intensamente.

\section{ESPACIO SOCIAL Y ÁREAS DE ACTIVIDAD EN LOS PATRONES DE ASENTAMIENTOS}

El estudio de los espacios domésticos en el extremo norte de Chile se ha abordado recientemente por Muñoz $(2004$; 2005) al estudiar los patrones de asentamiento de los períodos Medio y Formativo en el sector medio del valle de Azapa, Arica, señala una serie de indicadores de áreas de actividad lo cual ha permitido analizar sistemas de explotación y producción, división del trabajo, variabilidad socioeconómica, sistemas de intercambio, entre otros aspectos de la vida cotidiana. Por su parte, para los valles serranos Muñoz et al. (1997) han registrado componentes orgánicos y culturales relacionados a actividades que se pudieron haber generado dentro de los recintos, lo que ha permitido discutir la existencia y distribución de áreas preestablecidas como de descanso, ceremonial, cocina, almacenaje, trabajo y artesanía.

De lo anterior podemos señalar que el espacio doméstico constituye una evidencia fundamental para entender cómo se organizaron las poblaciones prehispánicas del extremo norte de Chile. Sin embargo, tenemos que tener presente la existencia de factores de índole social y cultural que influyen en la disposición del espacio en una unidad doméstica. Para Kent (1990: 5-7), por ejemplo, el uso del espacio doméstico está directamente relacionado con una variable cultural: la complejidad sociopolítica del grupo en cuestión. Según este modelo, es posible predecir cómo se organiza el espacio doméstico de un grupo determinado si se sabe cuál es su organización sociopolítica y viceversa.

El uso cultural del espacio doméstico es también abordado por Rappaport (1990), quien establece que la relación entre espacio doméstico y las actividades que se desarrollan es influenciada 
por la cultura (o más específicamente, las expresiones sociales de la cultura). El proceso de análisis de dicha relación parte del principio que es necesario considerar la forma en la cual un conjunto de acciones son organizadas en «sistemas de actividades», y estos, a su vez, en «sistemas de escenarios». Los sistemas de actividades se refieren a la necesidad de enfocarse no solo en las actividades por sí mismas, sino también en la forma en que éstas son ejecutadas, por quiénes, en qué momento y lugar, cómo son combinadas con otras actividades relacionadas y en qué secuencia ocurren. Los sistemas de escenarios están compuestos de combinaciones de sistemas de actividades y se refieren a aquellas situaciones donde determinada conducta toma lugar en concordancia con un conjunto de reglas preestablecidas y materializadas en el arreglo arquitectónico del espacio en cuestión. La argumentación teórica de Rappaport resulta especialmente útil para explicar la variabilidad existente en el uso del espacio doméstico entre culturas a pesar de realizarse en todas ellas actividades del mismo género.

Del análisis teórico anteriormente planteado y considerando los distintos componentes que conforman los poblados de la sierra de Arica, la información obtenida será clave pues nos ayudará a discutir y plantear hipótesis sobre cómo actuó dicha población en relación a su espacio social, problemática escasamente abordada por los estudios arqueológicos en la zonas altas de los valles occidentales andinos.

\section{LOS ASENTAMIENTOS DE ESTUDIO: METODOLOGÍA, UBICACIÓN Y CARACTERÍSTICAS GENERALES}

La metodología de terreno se centró en una primera etapa en un diagnóstico visual de los conjuntos arquitectónicos y de los restos culturales hallados en la superficie de los recintos, tanto internos como externos. En cuanto a la excavación, esta abordó en detalle los componentes culturales de las áreas de actividad doméstica, entre ellos los recintos o estructuras de vivienda, morteros, basurales, espacios de ofrendas, pozos de almacenaje, etc. Para tal efecto, se tomaron como unidades de referencia los recintos y/o estructuras más representativas en términos de patrón arquitectónico de los poblados. Se inició una etapa de limpieza para despejar el área de estudio, luego se hizo una descripción del recinto resaltando los lineamientos arquitectónicos, técnicas de pircado, cimientos, mampostería, tratamiento de la superficie donde se enclavaron dichos poblados; además de las piedras y vegetales utilizados en la construcción, accesos y vías de desplazamiento. Una vez definido el sistema constructivo del plano artificial que sustentaba la vivienda, se realizó un registro visual del piso ocupacional interno, intentando detectar testimonios de muros, postes y techumbre que conformaron la estructura física de la vivienda. Se llevaron a cabo excavaciones de reticulado alternado para definir los componentes estructurales de la vivienda y el material empleado.

En cuanto a la distribución y uso del espacio de la vivienda, se analizaron componentes como fogones, basurales, lineamientos de postes, morteros, pozos de almacenaje, ofrendas a la casa, etc., evidencias que nos permitieron establecer el espacio interior y exterior de la vivienda. Este análisis se abordó mediante el estudio de los componentes culturales y orgánicos hallados en las áreas preestablecidas como de descanso, cocina, alimentación y almacenaje. El método de excavación utilizado fue el de estacado perimetral total del recinto y la excavación fue a través de cuadrícula de $25 \mathrm{~m}^{2}$. El porcentaje de excavación en cada asentamiento alcanzó el 0,25\%. El control de la excavación y levantamiento de las evidencias se siguió a través de un mapeo y levantamiento topográfico utilizando un teodolito láser con software digital y posicionamiento mediante GPS. Para cada uno de los recintos se trabajó con una brújula magnética y altímetro manual. Este registro se complementó con la información de las mediciones topográficas y dibujo técnico de cada estructura (altura, espesores de muro, interno y externo, orientaciones de acceso o entradas, posibles techumbres, pasillos, escaños, estructuras interiores, collcas, etc.). El registro descriptivo de los recintos y del asentamiento general fue procesado de manera conjunta con el levantamiento y registro fotográfico. Además consideramos en estos registros la información 
proporcionada por lugareños, lo cual permitió tener una información etnográfica detallada de los sitios arqueológicos. Una vez realizados los levantamientos topográficos, sectorizamos las áreas de estudio con funciones de tipo económicas, viviendas, ceremoniales, vías de comunicación, posicionamiento estratégico, información apoyada por la cartografía de las áreas de estudio.

El poblado de Huaihuarani (N: 7957438. 5 m E. 444.184. 3 m) se sitúa en la margen norte del río Belén distante a $4 \mathrm{~km}$ al noreste del pueblo actual de Belén (fig. 2). El espacio geográfico donde se halla el asentamiento corresponde a un plano, relativamente amplio, siendo la margen este del río que concentra la mayor cantidad de terrazas y corralones. Las últimas cotas de los cerros, llegan a las proximidades del río en cortes de 3 a $4 \mathrm{~m}$ de altura.

El asentamiento prehispánico se encuentra en un imponente macizo rocoso que se adentra en dirección del valle, este a oeste, originando un meandro en el curso del río. La estructura granítica forma parte de la cadenas de montañas ribereñas de los diferentes valles andinos. Rodeando estos grandes cerros, existen pendientes más transitables y no tan inclinadas que son parte de faldeos de cerros más bajos. Específicamente el poblado de Huaihuarani se asienta sobre dos espolones rocosos, teniendo el que se ubica hacia el este mayor concentración de estructuras tanto en la cima como en los bordes y laderas. En cambio, el montículo más alto que presenta la cima estrecha se ubica hacia el oeste y presenta un alto número de estructuras nucleadas y sectorizadas producto de las características complejas del terreno.

El poblado prehispánico de Lupica ( $\mathrm{N}$ : 7953650. 0 m E: 444500. 0 m) está inserto en el valle de Lupica en su margen sur, y emplazado sobre un promontorio de color gris rosáceo de origen volcánico, el cual extiende su mayor longitud de norte a sur (fig. 3). Desde el sur, el promontorio es relativamente bajo, mientras que en su centro alcanza la mayor altitud. Luego vuelve a descender suavemente para remontar en un espolón más bajo, pero con bifurcación hacia el este. La ladera oeste del peñón es mucho más accidentada y de corte casi vertical que la banda contraria, es decir, el Este. Su pendiente de cotas medias probablemente esté alrededor de los $30^{\circ}<$ pero hacia la cima la roca se alza verticalmente por unos 15 a $20 \mathrm{~m}$ para luego declinar en dirección a la cima. Es en esta ladera que poblaciones andinas, planificando estructurar una urbe, edificaron sus viviendas, depósitos de almacenaje, corrales y espacios funerarios.

El asentamiento de Saxamar (N: 7950350. 2 m., E: 444850. 2 m) se ubica en los altos promontorios que dividen los ríos Saxamar y Tignamar. Estos ríos tienen sus nacientes a los pies de la cordillera Central (Los Andes) (fig. 4). El promontorio donde se ubica el asentamiento, forma parte de las estribaciones que provienen del cordón cordillerano en dirección oeste rematando en una extensa pampa. Estas cuencas de montañas dan origen a valles fértiles como Tignamar y Saxamar, cuyos poblados se ubican a $5 \mathrm{~km}$ al oeste del asentamiento prehispánico de Saxamar. Ocupando uno de los últimos promontorios, una antigua población local configuró un gran poblado sustentando su permanencia mediante el desarrollo agrícola y ganadero.

\section{DESCRIPCIÓN DE LAS ESTRUCTURAS DOMÉSTICAS Y ÁREAS DE ACTIVIDAD}

El presente capítulo describe de manera sintética las evidencias arqueológicas halladas en los asentamientos; la información de detalle se describe en la Tabla 1. Respecto a la funcionalidad de los recintos para estimar la población que vivió en dichos asentamientos resulta aún complejo por la falta de evidencias e interrelación misma de los recintos, motivo por el cual trataremos de dar una respuesta de tipo general cuando se trate de la discusión de la unidad doméstica. 


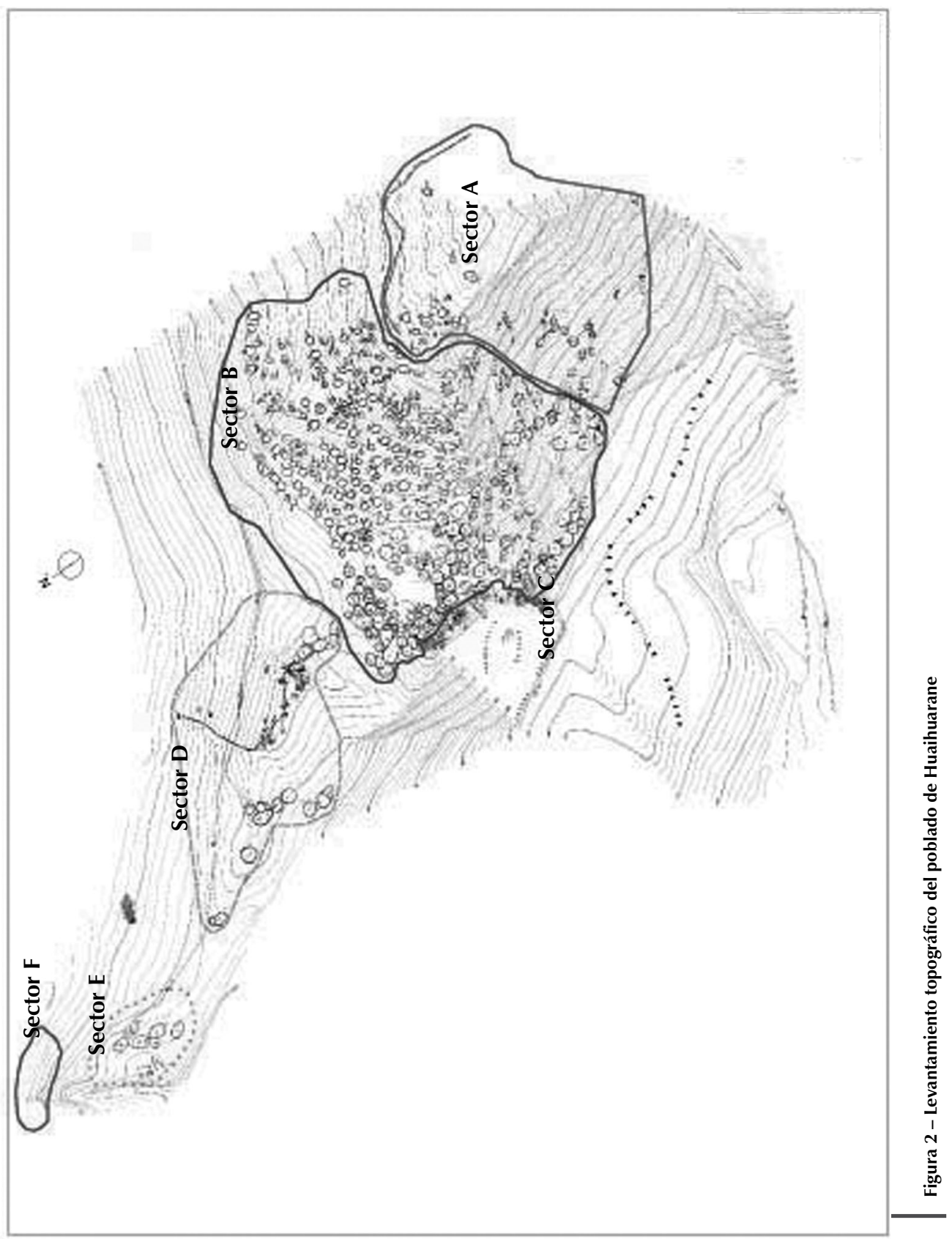




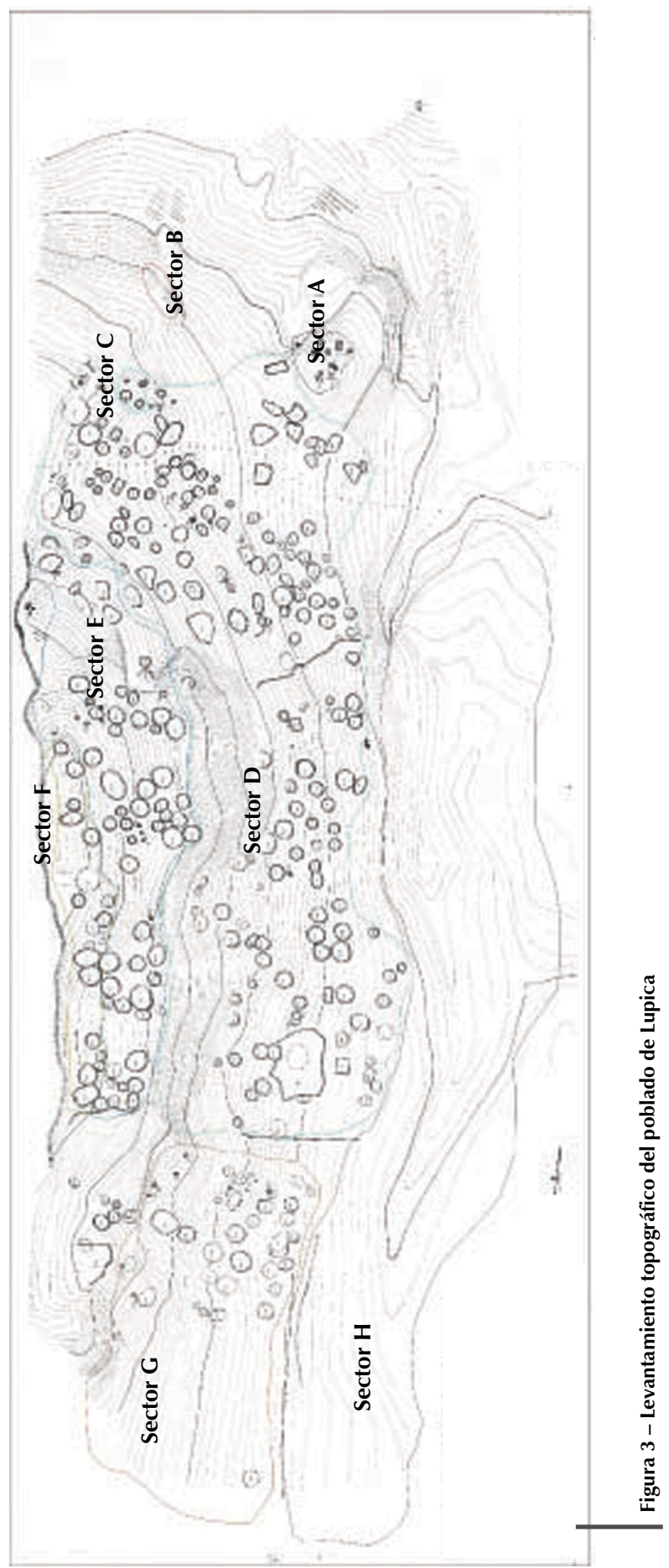




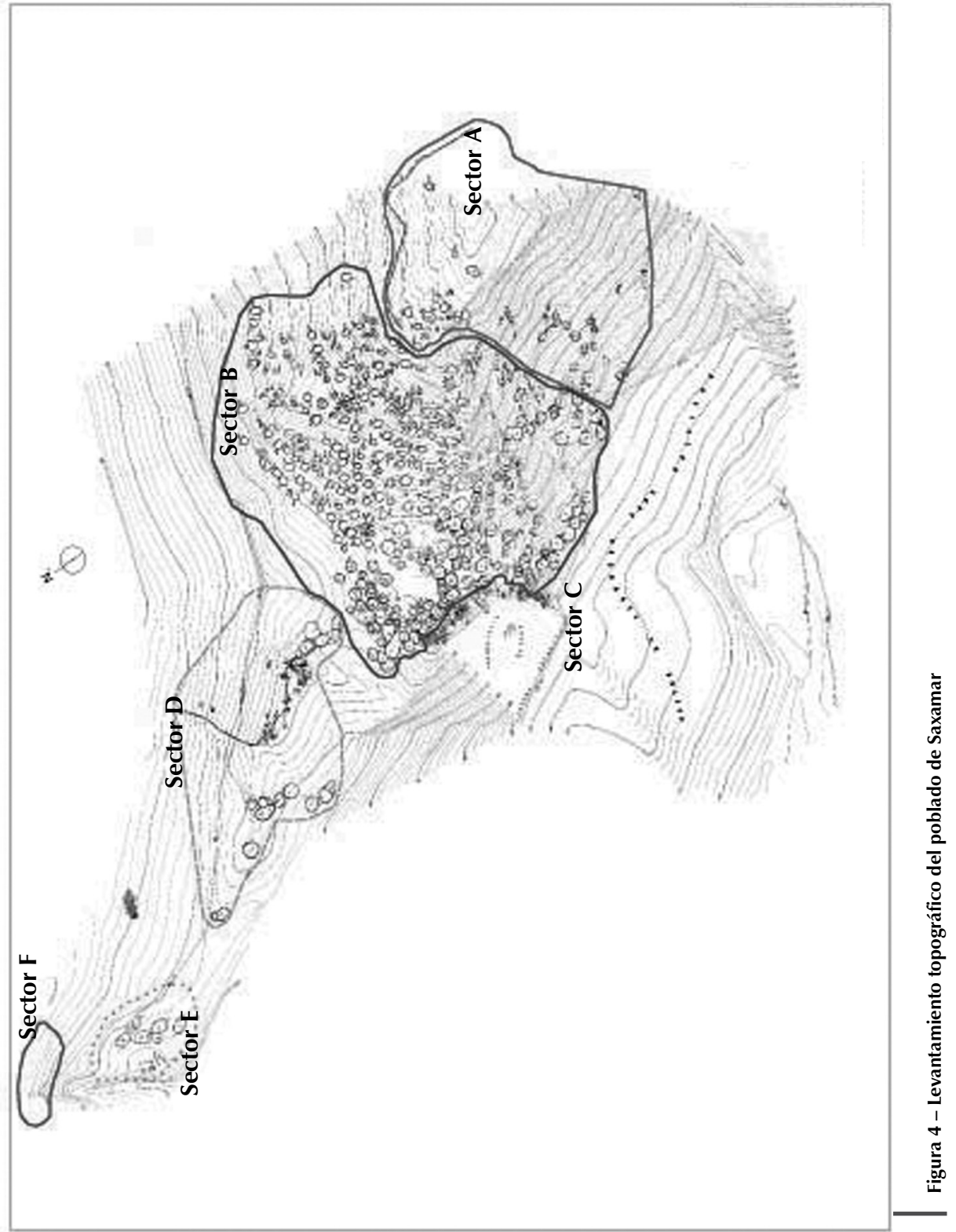


Tabla 1 - Análisis porcentual de las estructuras de los asentamientos Saxamar, Lupica y Huaihuarani

\begin{tabular}{|c|c|c|c|c|c|c|}
\hline \multirow{2}{*}{ Caractarísticas } & \multicolumn{2}{|c|}{$\begin{array}{l}\text { Huaihuarani } \\
598 \text { Estructura }\end{array}$} & \multicolumn{2}{|c|}{$\begin{array}{c}\text { Lupica } \\
353 \text { Estructura }\end{array}$} & \multicolumn{2}{|c|}{$\begin{array}{c}\text { Saxamar } \\
731 \text { Estructura }\end{array}$} \\
\hline & N.E. & $\%$ & N. E. & $\%$ & N. E. & $\%$ \\
\hline \multicolumn{7}{|l|}{ Formas } \\
\hline Oval (habitacional y silos) & 94 & 15,7 & 148 & 41.3 & 124 & 16,9 \\
\hline Circular (habitacional y silos) & 399 & 66,7 & 168 & 47,5 & 573 & 78,6 \\
\hline Rectangular (habitacional) & 94 & 15,8 & 31 & 9,6 & 28 & 3,9 \\
\hline Semirectangular (corrales y plaza) & 11 & 1,8 & 6 & 1,6 & 6 & 0,6 \\
\hline Total & 598 & 100,0 & 353 & 100,0 & 731 & 100,0 \\
\hline \multicolumn{7}{|l|}{ Dimensión de estructuras } \\
\hline $0-1,50 \mathrm{~m}$ & 104 & 17,5 & 17 & 4,8 & 278 & 38,0 \\
\hline $1,51-3,00 \mathrm{~m}$ & 34 & 5,7 & 46 & 13,0 & 80 & 11,2 \\
\hline $3,10-4,50 \mathrm{~m}$ & 112 & 18,9 & 50 & 14,1 & 87 & 11,9 \\
\hline $4,51-6,00 \mathrm{~m}$ & 170 & 28,7 & 76 & 21,6 & 135 & 18,4 \\
\hline $6,10-7,50 \mathrm{~m}$ & 106 & 17,5 & 92 & 26,1 & 70 & 9,5 \\
\hline $7,51-9,00 \mathrm{~m}$ & 45 & 7,6 & 41 & 11,7 & 55 & 7,5 \\
\hline 9,10 & 27 & 4,1 & 31 & 8,7 & 26 & 3,5 \\
\hline Total & 598 & 100,0 & 353 & 100,0 & 731 & 100,0 \\
\hline \multicolumn{7}{|l|}{ Sistema Constructivo } \\
\hline Muro doble hilada de piedras (habitación) & 47 & 7,8 & 269 & 76,2 & 401 & 54,9 \\
\hline Muro una hilada de piedras (habitación) & 467 & 77,7 & 63 & 17,9 & 323 & 44,2 \\
\hline Muro triple hilada de piedras (habitación) & 84 & 14,5 & 21 & 5,9 & 7 & 0,9 \\
\hline Total & 598 & 100,0 & 353 & 100,0 & 731 & 100,0 \\
\hline \multicolumn{7}{|l|}{ Espesor de muro } \\
\hline 10 a $20 \mathrm{~cm}$ & 109 & 17,2 & 24 & 6,6 & 21 & 40,5 \\
\hline 25 a $35 \mathrm{~cm}$ & 47 & 7,2 & 10 & 2,6 & 292 & 43,8 \\
\hline 40 a $50 \mathrm{~cm}$ & 322 & 54,4 & 140 & 39,8 & 322 & 10,2 \\
\hline 60 a $70 \mathrm{~m}$ & 82 & 14,5 & 157 & 44,9 & 74 & 2,2 \\
\hline 75 a $90 \mathrm{~cm}$ & 38 & 6,5 & 22 & 6,1 & 22 & 3,3 \\
\hline Total & 598 & 100,0 & 353 & 100,0 & 731 & 100,0 \\
\hline \multicolumn{7}{|l|}{ Orientación de las entradas } \\
\hline Ingreso habitaciones dirección SE & 94 & 15,7 & 25 & 7,1 & 47 & 6,4 \\
\hline Ingreso habitaciones dirección SO & 47 & 7,8 & 23 & 6,5 & 34 & 4,6 \\
\hline Ingreso habitaciones dirección $\mathrm{N}$ & 60 & 10,0 & 8 & 2,2 & 36 & 3,5 \\
\hline Ingreso habitaciones dirección NE & 94 & 15,7 & 19 & 5,3 & 27 & 3,6 \\
\hline Ingreso habitaciones dirección S & 30 & 5,0 & 21 & 5,9 & 58 & 7,9 \\
\hline Ingreso habitaciones dirección NO & 34 & 5,6 & 8 & 2,2 & 23 & 3,1 \\
\hline Ingreso habitaciones dirección O & 43 & 7,2 & 10 & 2,8 & 21 & 2,8 \\
\hline Ingreso habitaciones dirección E & 50 & 8,3 & 9 & 2,5 & 50 & 6,8 \\
\hline Indeterminadas & 146 & 24,7 & 230 & 65,5 & 435 & 61,3 \\
\hline Total & 598 & 100,0 & 353 & 100 & 731 & 100,0 \\
\hline \multicolumn{7}{|l|}{ Formas de Entradas } \\
\hline Simples & 206 & 34.5 & 105 & 29,7 & 26 & 3,5 \\
\hline Con jambas & 74 & 12.8 & 7 & 2,0 & 62 & 8,4 \\
\hline Apéndice & 33 & 5.5 & 10 & 2,9 & 21 & 2,8 \\
\hline Pasillos & 19 & 3.1 & 4 & 1,1 & 11 & 1,5 \\
\hline Indeterminadas & 266 & 44.1 & 227 & 64,3 & 611 & 83,8 \\
\hline Total & 598 & 100 & 353 & 100,0 & 731 & 100,0 \\
\hline \multicolumn{7}{|l|}{ Otras características } \\
\hline Estructuras pareadas & 215 & 33.9 & 140 & 38,4 & 273 & 37,3 \\
\hline Estructuras no pareadas & 97 & 16.6 & 28 & 8,2 & 82 & 11,1 \\
\hline Relación con muro perimetral & 3 & 0.7 & 65 & 18,2 & 118 & 15,8 \\
\hline División interior de las estructuras & 283 & 48.8 & 120 & 35,2 & 258 & 35,8 \\
\hline Total & 598 & 100 & 353 & 100,0 & 731 & 100,0 \\
\hline
\end{tabular}

N.E. Número de Estructuras 
El análisis porcentual indica las siguientes tendencias para estos tres asentamientos. Desde el punto de vista de la forma el mayor tipo es circular, siguiéndole el tipo oval; en relación a la composición de muros se destacan las de doble y una hilada de piedras; sin embargo, a pesar de que en Saxamar y Lupica la construcción a doble hilada es mayor que en Huaihuarani, el mayor porcentaje está constituido por muros a una hilada de piedras. En relación a los espesores de estos muros el mayor porcentaje se presenta entre los 25 a $30 \mathrm{~cm}$ y 40 a $50 \mathrm{~cm}$ en Saxamar y Lupica; en cambio en Huaihuarani los mayores se hallan en los $50 \mathrm{~cm}$. Las entradas presentan varias orientaciones como sur, norte, oeste, aunque con un leve porcentaje mayor hacia el noreste. En cuanto a las dimensiones de las estructuras, la mayoría de las estructuras de Saxamar alcanza los 1,50 m. En cambio en Huihuarani y Lupica, desde los 3 hasta los 7,5 m, los porcentajes son similares, lo que indica que los pozos de almacenaje en varios casos alcanzaron las dimensiones de las estructuras de viviendas (fig. 5).

Las entradas se caracterizan por formas simples, con jambas o pasillos, aunque en un gran número de estructuras no fue posible definirlas. Las divisiones interiores son escasas, registrándose un máximo de $10 \%$ del total de los asentamientos. A su vez las

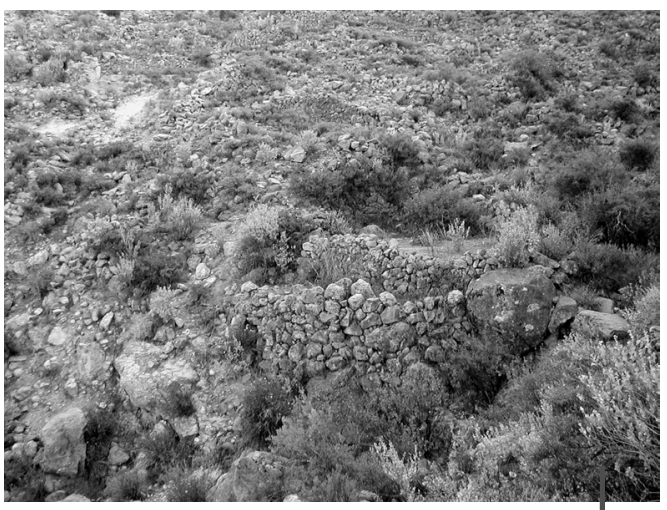

Figura 5a - Mampostería externa de recinto en área residencial asociada a promontorio principal del sitio Huaihuarani estructuras pareadas alcanzan un tercio del total de las estructuras por asentamientos.

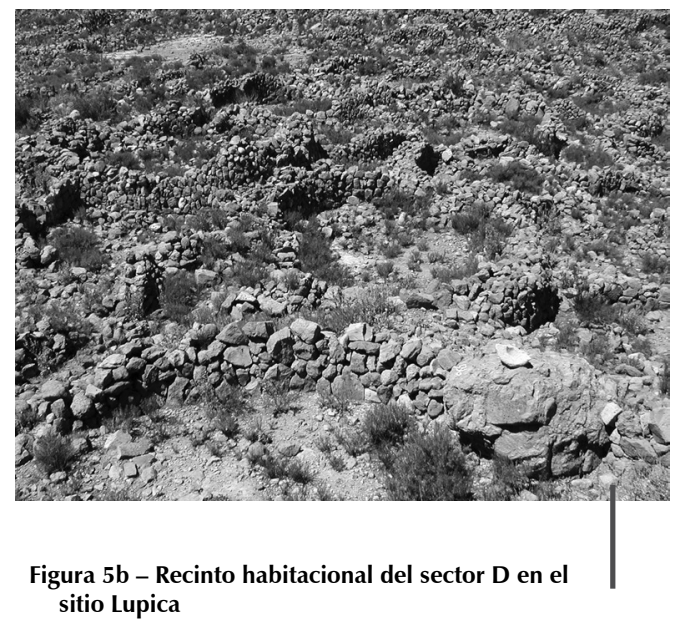
sitio Lupica

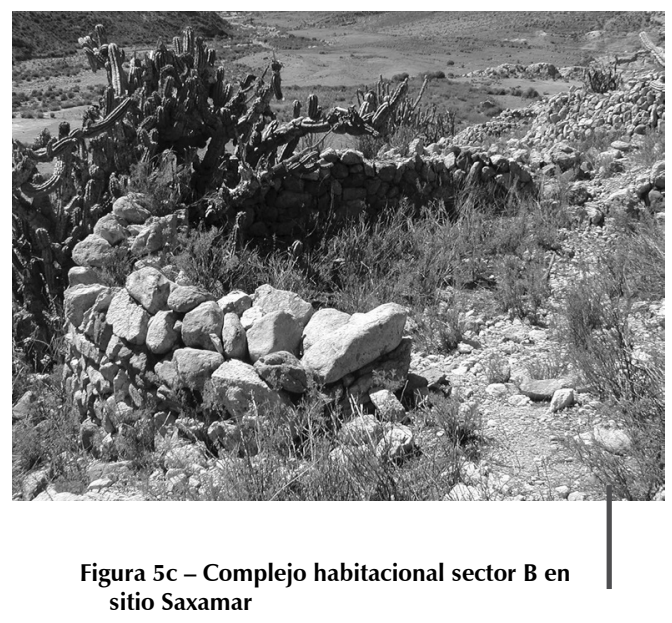

sitio Saxamar

\section{1. El patrón habitacional}

En Huaihuarani se registraron 598 estructuras, en Lupica 353 y en Saxamar 731 (Tabla 1). En cada uno de los sitios se excavó un porcentaje equivalente al 0,25 \%, información que dio evidencias para discutir las tendencias relacionadas al comportamiento de los sitios. Debemos señalar que en su gran mayoría la información estratigráfica, como basura, fue escasa, constituyéndose en la información más importante las evidencias superficiales de los recintos como cerámica, artefactos de molienda y fogones. 


\section{1. 1. Las estructuras habitacionales de Huahuarani}

Se ubican en los faldeos norte del cerro, específicamente hacia el este del macizo principal. Las viviendas han sido distribuidas a partir de un espacio amplio delimitado de forma oval.

Pueden observarse nueve niveles de piso ocupacional alcanzando las proximidades de la cima. El sentido de planificación urbana se orienta de este a oeste. El patrón arquitectónico varía desde estructuras de forma ovaladas a circulares; a su vez los muros presentan gruesa textura determinada por el empleo de bloques cuyas dimensiones son aproximadamente 60 por $70 \mathrm{~cm}$. Estos muros han sido construidos en doble hiladas de piedras, en cuyo interior presentan relleno de material de grava. Sobre el piso ocupacional interno, se halla bastante fragmentación de cerámica sin decoración, de color naranja, producto de la cocción de la arcilla.

Los accesos se orientan de este a oeste, de acuerdo al sentido de la orientación de la ladera. Algunos recintos, como el caso de R. 28, poseen estructuras menores de planta de forma circular, estructuras que al parecer fueron utilizadas como depósitos de almacenaje.

Llama la atención que en la edificación de estos recintos los muros fueron construidos a partir de rocas de gran volumen, incluso en muchos casos, los cimientos han sido asentados sobre afloramiento del suelo rocoso.

Los recintos habitacionales 12 y 13 difieren de otras estructuras en la construcción de sus muros. Las secciones norte utilizan rocas pequeñas en doble hilada de piedras, pero el relleno es material árido grueso (ripio). Debido a la nivelación del piso interno, este es más bajo que la superficie externa, por tal razón, se utilizaron uno o dos peldaños para acceder a las estructuras. Siguiendo en sentido este, a través del sendero principal, uno comienza a adentrarse por una quebradilla de pendiente no muy inclinada, que por su costado sur cae en forma inclinada.

El espacio habitacional ubicado en la pendiente de la ladera intermedia entre el macizo principal y el cerro orientado hacia el este, donde se ubican los sectores A, B y C, se caracteriza por un espacio relativamente estrecho, muy prominente, con una fuerte caída hacia el lecho de una quebradilla que desemboca en el margen este del río Belén, abriéndole paso a los pies del macizo. En este espacio se definieron 11 niveles de piso ocupacional, teniendo en las cotas superiores un espacio sin ocupación, producto de un escarpe rocoso. El sentido urbanístico se orienta en su eje mayor de sureste a noreste.

En sí, las viviendas responden a un patrón semicircular u oval, con muros construidos a doble hiladas de piedras con relleno de material de grava, lo que permite una estructura sólida. Visto en corte, los muros tienen un aplomo contrario a la caída de la pendiente. Sobresalen por altura las terminaciones de los muros oeste, llegando a alcanzar una altura externa, en algunos casos de hasta $2 \mathrm{~m}$. Las entradas a ellos quedan orientadas en los extremos norte y sur definidas con jambas y peldaños para adentrarse en pisos internos más bajos que los externos. Muchas estructuras comparten muros medianeros tanto por sus costados como en sus cimientos o bases que miran a la caja de la quebradilla. Esto le confiere al sector un aspecto aterrazado.

Otro espacio donde se concentra un alto conglomerado habitacional son las paredes del macizo principal. Este espacio, junto al sector D, está comunicado por senderos. Las estructuras existentes en este sector dan la percepción de constituir una plaza bien definida compuesta por pircados de doble hilada de piedra. También constatamos estructuras habitacionales de planta oval y trapezoidal distribuidas en tres niveles. Señalemos que en este sector los espacios para estructurar recintos se dieron de acuerdo con el relieve abrupto que presentaba la superficie del cerro. Una vía flanqueada con pirca por su costado sur, da acceso al macizo principal asignado como sector $\mathrm{F}$.

En cuanto a la ocupación interna de las estructuras, en 10 de ellas se hallaron restos de fogones; estos corresponden a manchones de cenizas con restos orgánicos quemados de aproximadamente 3 a $5 \mathrm{~cm}$ de espesor. Pudimos determinar 49 artefactos de molienda, todos ellos distribuidos a lo largo de los recintos habitacionales, 11 de ellos de forma cónica y 38 de forma de batán con los que, al parecer, molieron maíz. De acuerdo con las evidencias de las excavaciones y pozos de 
sondeo realizados en distintos sectores del emplazamiento habitacional, vemos una ocupación de carácter horizontal de amplia magnitud pero con escaso depósito de ocupación, lo que hace complejo determinar la intensidad de la ocupación.

\section{1. 2. La cerámica doméstica de Huaihuarani}

En nuestro estudio se recolectaron 294 fragmentos de cerámica tomados de siete recintos: 7, $51,148,263,342,391$ y 421 . Todos los fragmentos fueron encontrados en la superficie al interior de los recintos. Se consideró esta muestra reducida debido a los estudios previos que se enfocaron al igual que el nuestro en la identificación de pastas, formas y estilos decorativos.

Pastas. El mayor número corresponde a los tipos 104 (51 fragmentos) y 105 (43 fragmentos). En general es una cerámica de pasta compacta, brochada en su superficie, con estrías y superficies espatuladas, la pasta es arenosa con mica. El 30 \% presenta porosidad en sus caras internas y externas. La pasta es de color rojizo, naranja, negro y gris, la gran mayoría está dada por un sistema de brochado en su superficie.

Formas. El mayor número corresponde a fragmentos de cuerpo. El $35 \%$ presenta formas de olla y el $5 \%$ de puco, el $3 \%$ corresponden a formas de tazón y escudillas. No se pudo identificar las formas del resto, equivalente a un $57 \%$. Respecto a formas de base se identificaron 5 fragmentos de base recta y 3 bordes de forma redonda.

Estilos. Los estilos reconocidos fueron 21 fragmentos, 13 corresponden a Charcollo, 4 a Chilpe, 2 a Inca Local y 2 a Saxamar. Presentan buen tratamiento de la cocción de la pasta, las superficies externas están brochadas con engobe que cubre la totalidad de la superficie de la cerámica en su cara externa.

Estudios Previos. Una primera aproximación al estudio de la cerámica de superficie en el asentamiento de Huaihuarani, fue representado por Dauelsberg (1983: 77-78) quien señala que de 29 fragmentos recolectados de cerámica decorada, el mayor estilo lo constituye el Chilpe (13 fragmentos), luego vendría el Inca-Saxamar y Negro sobre Rojo (5 fragmentos cada uno), el estilo San Miguel que presenta 4 fragmentos, Pocoma-Gentilar con 1 fragmento y otro que no presentaba claro su estilo. En cuanto a la cerámica no decorada se recolectaron 273 fragmentos, presentando 129 fragmentos brochado grueso, 114 alisado húmedo, 23 compacta sin engobe rojo, 5 compacta con engobe rojo, 1 fragmento presenta superficie quebrajada y 1 no fue identificado.

Respecto a este mismo sitio, Romero (1999: Tabla 3), al estudiar la variable estilística y la distribución cerámica, señala las características generales de la muestra cerámica del sitio. De acuerdo a la información entregada, señala la sectorización del sitio desde el A al G, la recolección de fragmentos de cerámica se hizo superficialmente en 81 recintos, alcanzando un total de 3237 fragmentos. Reconoce tres tradiciones tecnológicas. La primera —estándar 200 - es de origen altiplánico asociada a decoraciones tales como Saxamar, Inca altiplánico y las variantes del Negro sobre Rojo como Chilpe y Vila Vila. La segunda parece corresponder a una tecnología de valle bajo con desgrasante de arena que da un cocimiento entre rojizo y naranja; se asocia a los estilos San Miguel y Pocoma. La tecnología serrana constituiría el estándar 500 privilegiando el desgrasante con alta cantidad de cuarzo con una cocción irregular; según Romero se podrían asociar al estilo Charcollo, algunas variantes del Negro sobre Rojo y con engobe rojo grueso. En cuanto a la distribución de la cerámica, señala que la pasta altiplánica es baja en las áreas residenciales, por ejemplo en el sector A, al disminuir la tradición de valle bajo, la pasta con técnica serrana aumenta, mientras que en el sector $\mathrm{E}$ ambas pastas muestran similares proporciones. Plantea que al tomar el rasgo de la decoración también resaltan algunas diferencias, por ejemplo, en el sector A los estilos más representativos corresponden a la tradición Negro sobre Rojo, mientras que en el sector E existe un alto porcentaje del estilo Charcollo. Señala además una baja presencia del estilo Desarrollo Regional Costero. Respecto a las formas se remarca más lo altiplánico en el sector A, mientras que en el sector E se remarca más la tradición de valles bajos. 


\section{1. 3. Las estructuras habitacionales de Lupica}

Ocupan la totalidad del peñón abrupto quedando orientadas hacia el este, es decir hacia el valle. Son edificios de planta oval, circular y en menor número rectangulares, estas últimas están ubicadas en la base del sector $\mathrm{C}$, esquina sureste. En 11 niveles topográficos, se distribuyen las viviendas cuya prolongación mayor está orientada de sur a norte. Los muros fueron construidos con pircados a doble hilada de piedra, aplomados en sentido contrario a la pendiente del cerro. Obviamente las accesos a las viviendas obedecen al sentido de nivelación superficial norte-sur; a su vez los bloques dispuestos como jambas los empotraron verticalmente. Los pisos de ocupación en el interior de los recintos poseen una tonalidad blanquecina asociada a fragmentación ceramológica decorada y no decorada. Existen claros corredores de comunicación que se entrelazan con otros tangencialmente, manteniendo movilidad desde las cotas superiores a las inferiores.

Un espacio de planta circular ocupa un área intermedia de unión entre el promontorio principal y el promontorio menor. Podríamos definir este espacio como plaza o lugar de interacción social. Los muros son gruesos, de doble pircado de piedra, pero bajos de altura.

La mayor densidad de estructuras se halla desplazada de norte a sur en nueve niveles en los dos mayores montículos donde se asentó la población de Lupica. Los muros fueron construidos a doble hilada de piedras, algo separada para dar cabida a un vaciado considerable de tierra y sedimento. Varias estructuras conforman entre sí aterrazamientos, producto que nacen de las bases de otras (p. ej., R. 180-190). Los accesos fluctúan de norte a sur, existen pequeñas estructuras circulares construidas muy próximas a las viviendas que definimos como silos o depósitos de almacenaje. Dentro y fuera de los recintos hemos hallado batanes para molienda de gramíneas (harina) (p. ej., R.180). Escasos recintos — como el 223- se hallan en la cima de este cerro, puesto que su geomorfología es muy estrecha.

Entre el sector E y F se produce un claro afloramiento natural rocoso cuyas paredes caen verticalmente. En este espacio se hallan estructuras de planta de forma oval a doble hilada de piedras, distribuidas desde la cima y hacia cotas inferiores. Los pircados son gruesos, bien terminados, con bastante sedimentación depositada entre las hiladas. Todo el sentido de orientación de las estructuras está dada hacia el este, en 8 nivelaciones. En este espacio, un buen número de estructuras quedaron al borde del acantilado. Los accesos están claramente definidos, incluso con algunas prolongaciones a modo de pasillos. Los pisos ocupacionales en el interior de las estructuras presentan fragmentación de cerámica de pastas rojas con decoración en negro, además de algunos restos de batanes para la molienda de gramíneas.

Al extremo sur del promontorio las cotas comienzan a bajar con algunos relieves abruptos sobresalientes. Son escasos los recintos construidos en este sector, y se conservan en muy mal estado. Solo cimientos a doble hilada de piedras con algunos segmentos de muro constatamos en los R. 262 y 263.

Por el sector sur de la ladera este del promontorio algunos muros que sirvieron de contención o de terraplén para la construcción de 15 estructuras circulares con pircado a doble hiladas de piedra, presentan cuerpo abovedado, y están construidas pegadas a las bases de algunas paredes rocosas. Pensamos que estas estructuras podrían corresponder a silos. En el R. 303 ubicado en este sector, el piso de ocupación superficial es esencialmente orgánico, allí hemos hallado restos de zuros de maíz, coprolitos de camélidos y fecas de fauna nativa (vizcachas).

La ocupación interna de las estructuras presenta fogones en 8 de ellas que se caracterizan por manchones de cenizas, carbones y material orgánico quemados de aproximadamente 3 a $6 \mathrm{~cm}$ de espesor. En cuanto a la presencia de artefactos de molienda pudimos determinar 39, todos ellos distribuidos a lo largo de los recintos habitacionales, 11 de ellos de forma cónica y 28 de forma de batán. Al igual que Huaihuarani las evidencias de las excavaciones y pozos de sondeo en distintos sectores del emplazamiento habitacional indican una ocupación de carácter horizontal de amplia magnitud pero con escasa estratigrafía ocupacional. 


\section{1. 4. La cerámica doméstica de Lupica}

Se recolectaron 1650 fragmentos de cerámica. El $70 \%$ provienen del sector central del poblado.

Pastas. Los mayores estándares de pasta corresponden a los tipos 104 (44 \%), 105 (32\%) y 103 (17\%). Corresponden a cerámicas de pastas compactas manufacturadas en arcillas con arena de granulometría fina y mica. En general presentan buena cocción y un pulido con espátula.

Formas. El mayor número de fragmentos (1 490) corresponde a la parte central de cuerpos de ceramios, 141 fragmentos constituyen bordes, 21 fragmentos base y 26 asas de forma acintada. Se reconocieron 72 fragmentos de ollas, 39 formas globulares, 14 fragmentos de pucos, 8 jarras, 4 escudillas y un fragmento de aríbalo. Al igual que los otros asentamientos estudiados la presencia de formas globulares, ollas y jarras, remarcaría una alfarería con función doméstica, objetos que fueron empleados para preparar comidas, trasladar agua y tal vez para guardar alimentos. La presencia de material orgánico adherido en la superficie interna de la cerámica apoyaría esta hipótesis, lo mismo que la presencia de hollín adherido en la superficie externa de los fragmentos cerámicos, lo que demostraría que fueron expuestos al calor de las brazas.

Estilos. Se reconocieron 182 fragmentos decorados, 88 correspondieron al estilo Charcollo, 24 al Inca Local, 13 al estilo Chilpe, 7 al estilo Saxamar, 6 al estilo Gentilar, 4 al estilo Negro sobre Rojo, 3 al estilo Pocoma-San Miguel y 2 al estilo San Miguel. Debido a la alteración de la decoración, 35 fragmentos no pudieron ser asociados a un estilo. De acuerdo con esta tipología se puede plantear un estilo local que correspondería al Charcollo constituyéndose en el estilo serrano propio de los valles altos de Arica tal como lo han postulado Dauelsberg (1983), Muñoz et al. (1997) y Romero (1999).

\section{1. 5. Las estructuras habitacionales de Saxamar}

Se distribuyen a partir de la cima del promontorio principal que ocupa la banda este del sitio. Junto a estas observamos un muro perimetral muy bien trabajado y conservado, especialmente en el sector noreste, que se ubica a 20 metros debajo de la cima. Las estructuras habitacionales las hemos identificados a nivel de planta. Estas responden a una forma semirectangular casi oval incluso pueden determinarse accesos definidos por bloques líticos a modo de jambas. No tienen gran altura, ocupan la cotas cercanas a la cima y se desplazan por la banda sur, este y norte (R. 261-267). Es posible que estas estructuras correspondan a la urbanización final del sitio. Los muros son a doble hilada de piedras con relleno de sedimentación lítica-terrosa. En estas estructuras tanto en su interior como fuera de ellas, vemos una gran fragmentación cerámica de tonos anaranjados y grises sin decoración. También en menor densidad lascado de obsidiana, algunos morteros y manos, artefactos ubicados preferentemente en la cima del cerro.

En la cima se halla un espacio sin ocupación — abierto — lo cual sugiere una función de mirador, controlador de espacio por los cuatro puntos cardinales, o bien un lugar ceremonial donde se celebraron rituales agrícolas relacionados con los ciclos de siembras y cosechas.

A mitad del peñón comienzan a nuclearse los recintos, aprovechando los diferentes niveles topográficos, extendiéndose hasta el borde superior del plano que baja desde la cima del promontorio principal. Este sector involucra un total de 76 estructuras, las cuales quedan vinculadas físicamente con el muro perimetral. En este sector se hallan pozos de almacenaje asociados directamente a los recintos habitacionales. Para construirlos, se realizaron fosas de forma circular pircando solamente los niveles superficiales.

En la ladera oeste del promontorio principal que se extiende hasta un extenso y estrecho plano, las estructuras se desplazan hasta la ladera norte del promontorio. En doce a trece niveles se distribuyen los diferentes recintos habitacionales y pozos de almacenaje. La planta arquitectónica es esencialmente de forma oval dejando accesos, ya sea por el noreste o suroeste y definiéndolos con bloques líticos empotrados verticalmente a modo de jambas. Los muros han sido construidos 
a dos hileras de piedras, aplomados en sentido contrario a la pendiente. Entre ambas hileras se depositó grava (ver R. 212-216).

En la planicie del cerro señalado como sector B observamos un conglomerado de estructuras de tipo residencial, éstas comparten muros como «medianeras» y entre ellos se producen estrechos pasillos de movilidad y comunicación. Otro aspecto importante como resultante de este criterio constructivo, es que las plantas arquitectónicas varían de ovales a irregulares constituyéndose en espacios amplios de morada. Las estructuras habitacionales del sector B que limitan a los pies del área funeraria, se extienden hacia la ladera sur del sitio, aproximadamente $60 \mathrm{~m}$ hacia cotas inferiores. Los muros se mantienen en buenas condiciones permitiendo visualizar técnicas de plomada, cimientos, distribución de cantos, accesos, plantas arquitectónicas, vías de desplazamiento entre recintos.

La ocupación interna de las estructuras presenta en 25 de ellas restos de fogones; estos corresponden a cenizas con restos orgánicos quemados de aproximadamente $4 \mathrm{~cm}$ de espesor. Pudimos determinar 79 artefactos de molienda, todos ellos distribuidos a lo largo de los recintos habitacionales, 29 de ellos de forma cónica y 50 de forma de batán con una leve cavidad para moler. De acuerdo con las evidencias que arrojaron las excavaciones y pozos de sondeo realizados a distintos sectores del emplazamiento habitacional vemos una ocupación de carácter horizontal de amplia magnitud pero con escasa ocupación de depósito, al igual que Huaihuarani y Lupica.

En cuanto al número de gente que vivió en estos poblados, es difícil realizar estimaciones, más aún cuando la muestra analizada en términos de excavación es menor $(0,25 \%)$. Además no todos los recintos fueron ocupados, sin embargo, nos aproximamos a una ocupación de menos de 100 personas. Esta estimación es realizada a partir de la presencia permanente de artefactos de molienda y cerámica en la superficie de aproximadamente 200 recintos. Esto debió haber ocurrido en 300 años de ocupación.

\section{1. 6. La cerámica doméstica de Saxamar}

Se recolectaron 1357 fragmentos de cerámica provenientes de distintos sectores de ocupación del sitio. La recolección fue superficial tomando el $20 \%$ del material cerámico hallado en el espacio interior del recinto.

Pastas. El estándar predominante es el tipo 104 equivalente a un $75 \%$ del total de los fragmentos, en menor cantidad los tipos 103 (11\%) y 105 (9 \%). La cerámica es de buena factura, en términos de pasta y cocción; presenta brochado.

Formas. Estas corresponden a 61 fragmentos de ollas, 24 fragmentos de cántaros globulares, 16 fragmentos de escudillas y 6 fragmentos de pucos. Estos fragmentos de cerámica presentan restos de material orgánico adherido en sus caras internas. Otras presentan restos de hollín, lo cual sugeriría una función doméstica.

Estilos. El mayor número de fragmentos (26) corresponde al estilo Charcollo, también se hallaron 2 fragmentos estilo San Miguel, Gentilar y Pocoma-San Miguel. Un fragmento está asociado al estilo Chilpe. No se pudo determinar el estilo de 7 fragmentos debido a la compleja decoración. Son fragmentos de pasta roja con engobe, la decoración se caracteriza por líneas y círculos de color negro. En este sitio más del 95 \% de la cerámica recolectada no está decorada.

La fig. 6, relacionada a los estilos de cerámica, permite visualizar que en los tres asentamientos observamos la presencia de tres tradiciones de cerámica: la costera, relacionada a los estilos San Miguel, Pocoma y Gentilar; la altiplánica, relacionada a los estilos Negro sobre Rojo; y la serrana, cuyo mayor representante es la cerámica Charcollo. Sin embargo, en el presente trabajo se ha integrado, bajo esta denominación, una serie de fragmentos monócromos que, desde el punto de vista tecnológico, son representativos de la Tradición Serrana (fig. 7). 

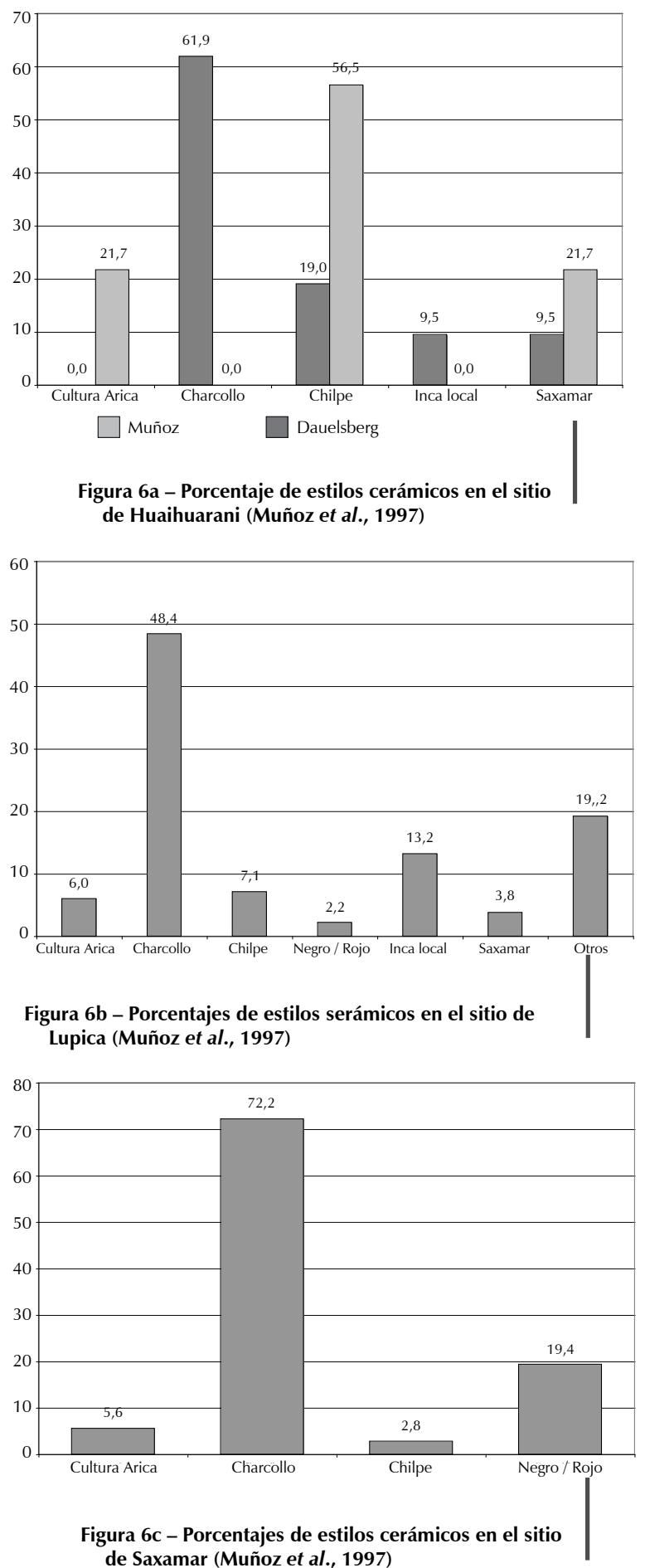

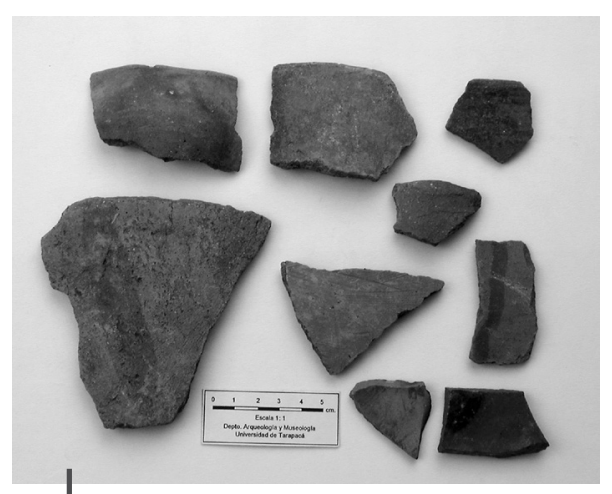

Figura 7a-Cerámica de tradición serrana, estilo Charcollo
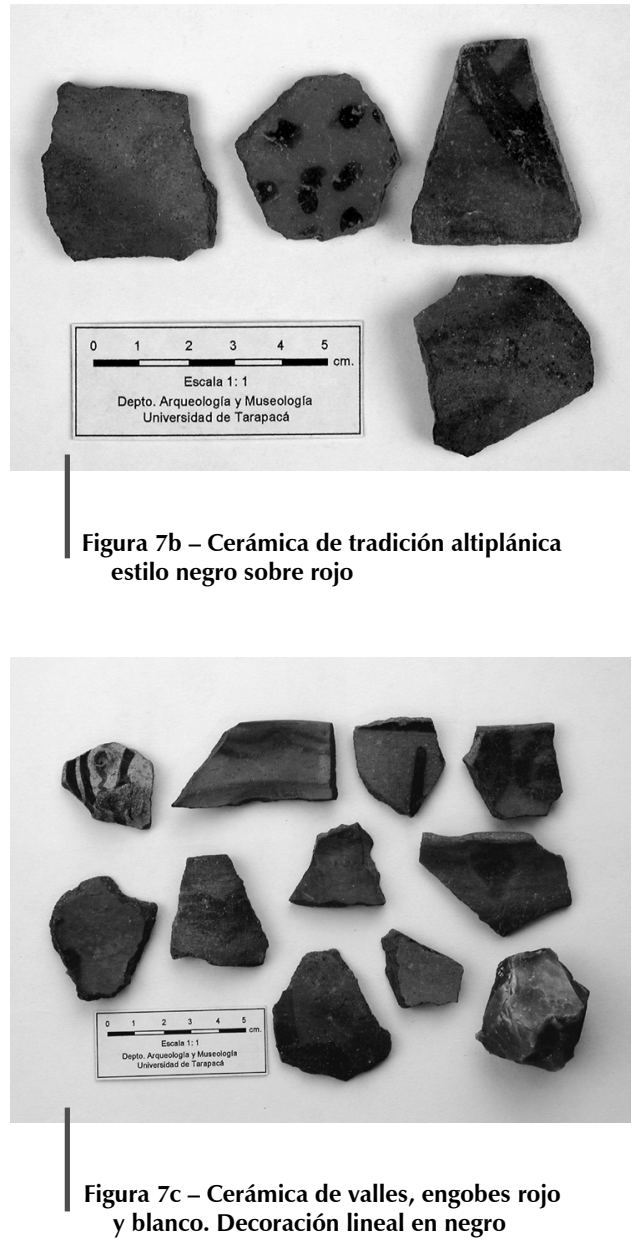


\section{FECHAMIENTO POR TL Y DISCUSIÓN CERAMOLÓGICA}

En la tabla 2 se muestran los fechados obtenidos para los asentamientos de Huihuarani, Lupica y Saxamar. Estos fechados fueron obtenidos por el método de la Termoluminiscencia (TL) en el Laboratorio de la Facultad de Física de la Pontificia Universidad Católica de Chile (fig. 8). Del asentamiento Huihuarani se tomaron cuatro muestras de cerámica: la primera corresponde a UCTL-796, proveniente del recinto 476, con una fecha TL 1440 d. C. (555 \pm 60 a. p.); correspondió a un fragmento con decoración estilo San Miguel, fondo blanco cremoso, con líneas paralelas

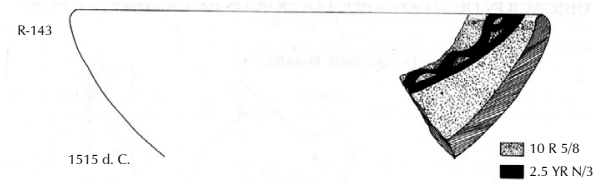

$\underset{R-428}{\frac{E S C 1: 20}{R-1}}$
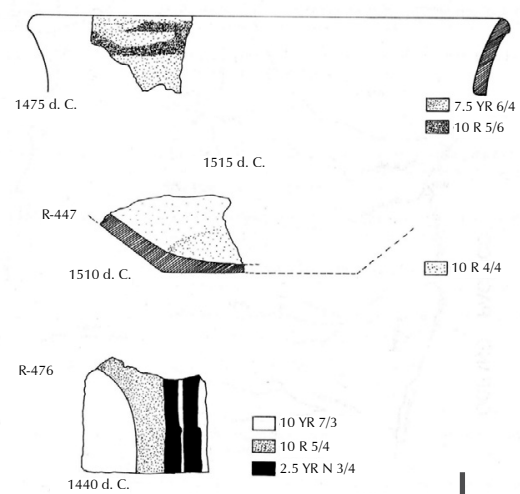

Figura 8a - Cerámica del poblado de Huaihuarani

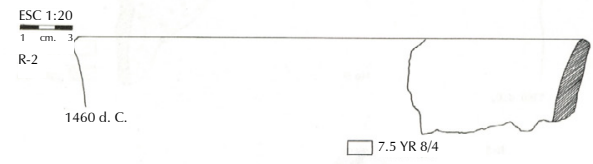

R-324
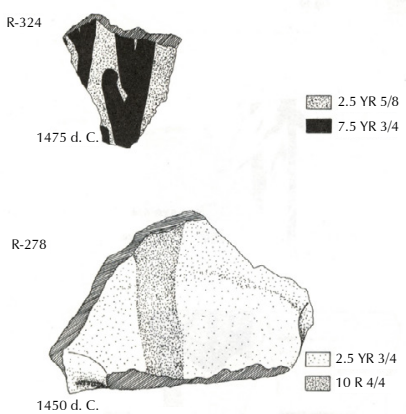

R-602

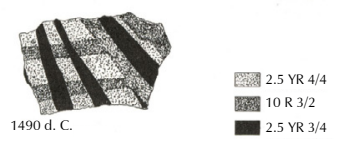

Figura 8b - Cerámica del poblado de Saxamar

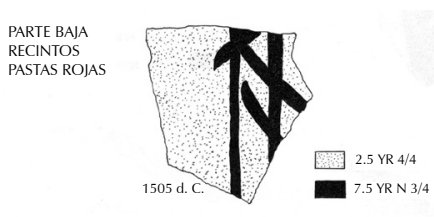

R-602

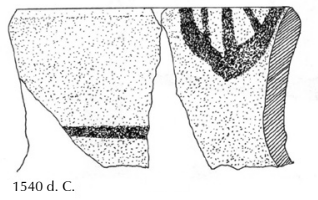

2.5 YR $4 / 4$
7.5 YR N $4 / 3$

Figura 8c - Cerámica del poblado de Lupica 
negras y rojas de forma curva, superficie externa pulida, cuidadosamente bruñida y superficie interna pulida no alisada; forma globular. La segunda muestra UCTL-797 proviene del recinto 143 y dio una fecha de 1515 d. C. (480 \pm 45 a. p.). Las superficies interna y externa presentan un pulido y bruñido, decoración interna con diseño en negro sobre la pasta, dispuestos en forma oblicua y líneas onduladas; corresponde a un puco. La tercera muestra UCTL-798 proviene del recinto 798 y dio una fecha de 1510 d.C (485 \pm 35 a. p.). Presenta un tratamiento de la superficie interna suave y bruñida. La superficie externa es suave, pulida y bruñida, sin decoración interna, presenta una película de engobe rojo en su interior, corresponde a un fragmento de base. La cuarta muestra UCTL-799 proviene del recinto 428 y dio una fecha de 1475 d. C. $(520 \pm 30$ a. p.). Presenta un tratamiento de la superficie interna y externa de un suave pulido y bruñido, la superficie externa presenta un estriado suave. En la cara externa presenta líneas horizontales, desordenadas de color rojo, muy diluido, corresponde a un fragmento de forma globular.

En Saxamar también se fecharon cuatro fragmentos. El primero UCTL-800 proviene del recinto 324 y dio una fecha de 1475 d. C. (520 550 a. p.), superficie interna y externa pulida y bruñida en forma burda, decoración interior en negro con grecas con gancho sobre engobado en rojo y naranja. Corresponde a un fragmento de cuerpo y se relaciona al horizonte Negro sobre Rojo altiplánico. La segunda muestra UCTL-801 proviene del recinto 602 y dio una fecha de 1490 d. C. $(505 \pm 60$ a. p), superficie interna pulida suavemente y la cara externa pulida con un bruñido suave; decoración externa, formada por un reticulado de líneas gruesas en negro y más delgadas en rojo y marrón, sobre superficie rojiza anaranjada; corresponde a un fragmento de cuerpo. La tercera muestra UCTL-802 proviene del recinto 2 y dio una fecha de 1460 d. C. $(535 \pm 55$ a. p.), superficie interna y externa alisada con un leve brochado y engobado; tiene engobe por ambos lados de color blanco cremoso. Corresponde a un fragmento de forma globular. La cuarta muestra UCTL-803 proviene del recinto 278 y dio una fecha de 1450 d. C. (545 \pm 55 a.p), superficie interna pulida alisada y superficie exterior pulida sin alisar, sin decoración en su cara exterior y en su cara interior un engobado en rojo naranja y decoración en negro de grecas con gancho, corresponde a un fragmento de cuerpo.

En Lupica se fecharon dos muestras. La primera UCTL-806 proviene de la parte baja de los recintos y dio una fecha de 1505 d. C. (490 550 a. p.), superficie interna pulida con brochado; se observan estrías, la superficie exterior tiene bruñido suave, con engobado solamente por la cara exterior de color rojo con decoración en negro de líneas paralelas y entrecruzadas. La segunda muestra UCTL-807 proviene del recinto 363 y dio una fecha de 1540 d. C. $(455 \pm 50$ a. p.). Tiene superficie interna y externa pulida sin alisar, bruñida, engobado en ambos lados de

Tabla 2 - Fechados TL para la cerámica de la sierra de Arica

\begin{tabular}{|l|c|c|c|c|}
\hline \multicolumn{1}{|c|}{ Sitio } & $\begin{array}{c}\text { Muestra } \\
\text { laboratorio }\end{array}$ & Descripción & Edad & Fecha TL \\
\hline Huaihuarani & UCTL-796 & Recinto 476 & $555 \pm 60$ & 1440 d. C. \\
\hline Huaihuarani & UCTL-797 & Recinto 143 & $480 \pm 45$ & 1515 d. C. \\
\hline Huaihuarani & UCTL-798 & Recinto 447 & $485 \pm 35$ & 1510 d. C. \\
\hline Huaihuarani & UCTL-799 & Recinto 428 & $520 \pm 30$ & 1475 d. C. \\
\hline Saxamar & UCTL-800 & Recinto 324 & $520 \pm 50$ & 1475 d. C. \\
\hline Saxamar & UCTL-801 & Recinto 602 & $505 \pm 60$ & 1490 d. C. \\
\hline Saxamar & UCTL-802 & Recinto 2 & $535 \pm 55$ & 1460 d. C. \\
\hline Saxamar & UCTL-803 & Recinto 278 & $545 \pm 55$ & 1450 d. C. \\
\hline Lupica & UCTL-806 & Sector bajo & $490 \pm 50$ & 1505 d. C. \\
\hline Lupica & UCTL-807 & Recinto 363 & $455 \pm 50$ & 1540 d. C. \\
\hline
\end{tabular}


color rojo con decoración en negro. En la cara exterior se halla una línea horizontal en la base del cuello, en el interior del borde se halla una figura lineal de forma triangular; corresponde a un borde de jarra.

\section{COMENTARIOS}

Del análisis de las fechas se desprende que los tres asentamientos coexistieron durante la influencia Inca, siendo Lupica el que tal vez perduró hasta después del $1500 \mathrm{~d}$. C. El promedio de las fechas de Huaihuarani es de 1476 d. C. y corresponden a estilos locales, influencia del horizonte Negro sobre Rojo (Reinos Postiwanaku) y de los valles bajos de Arica, que sugiere que en este poblado vivió una población local que se movió hacia la costa y puna. A pesar de su gran magnitud, desde el punto de vista de los recintos, la ocupación del sitio parece relativamente corta. En el caso del asentamiento de Saxamar el promedio de las fechas es 1468 d. C.; las características de la cerámica se asemejan mucho a los de Huaihuarani, lo que nos sugiere una ocupación local de los valles serranos que fue influenciada por grupos costeros del Pacífico y grupos altiplánicos asentados durante el período del Tawantinsuyo. Sin embargo no vemos una presencia representativa de cerámica cusqueña, lo que reafirmaría lo planteado: que en los valles altos de Arica la influencia incaica vino de parte de poblaciones provenientes del altiplano circumtiticaca, especialmente la población Carangas. En el caso de Lupica parecer ser que la población local coexistió más tardíamente acompañada por alfarería de la tradición Negro sobre Rojo del área circumtiticaca. Esta situación se pudo haber dado en el momento en que el Inca ya había influenciado los valles costeros y serranos de Arica. Sugerimos que los primeros contactos indígenas de los valles altos de Arica con los europeos se produjeran estando aún en actividad el poblado de Lupica y Huaihuarani.

\section{ENTIERROS}

En Huiahuarani, por el costado este del cerro, ubicamos dos complejos funerarios, cuyas construcciones se caracterizan por tener una planta circular con gruesos muros pircados en doble hilada de piedra. Cada una de las sepulturas se construyeron en torno a un crecimiento orgánico, están unidas entre sí, mediante un muro común. El estado general de conservación de estas estructuras funerarias es malo por causas de abatimiento de muros.

En Lupica los entierros se ubican en la cima del promontorio donde en un alero con osamentas humanas, presenta una superficie muy irregular; sin embargo aprovecharon los desniveles para levantar estructuras. El sector funerario corresponde al sector A y está ubicado al noroeste, inserto en aleros naturales de un promontorio o espolón rocoso más pequeño (fig. 9). Estos aleros están orientados hacia el noreste, mirando al valle. Se utilizó un estrecho pero largo alero en que su entrada fue sellada con un pircado a doble hilada de piedras para mantenerlo aislado del medio. Las excavaciones permitieron visualizar parte del cimiento de este pircado. En él fueron hallados restos de material orgánico. De los restos humanos dispersos, se contabilizaron seis cráneos deformados, muy blanquecinos, producto de una prolongada exposición al sol. Acompañan estos cráneos mandíbulas y huesos largos (fémures). Dentro del alero los cuerpos fueron depositados individualmente en una estructura de planta circular o pentagonal, cistada por piedras lajas y adosándolas a un muro medianero. Esta construcción se hizo a partir de la línea de tierra del alero.

Junto a las osamentas, en el suelo, detectamos fragmentación de cerámica no decorada color naranja con tonalidades grises debido a la cocción. Este alero es la única evidencia concreta del lugar de enterramiento. Otros aleros más pequeños no contenían información relacionada a entierros humanos. 

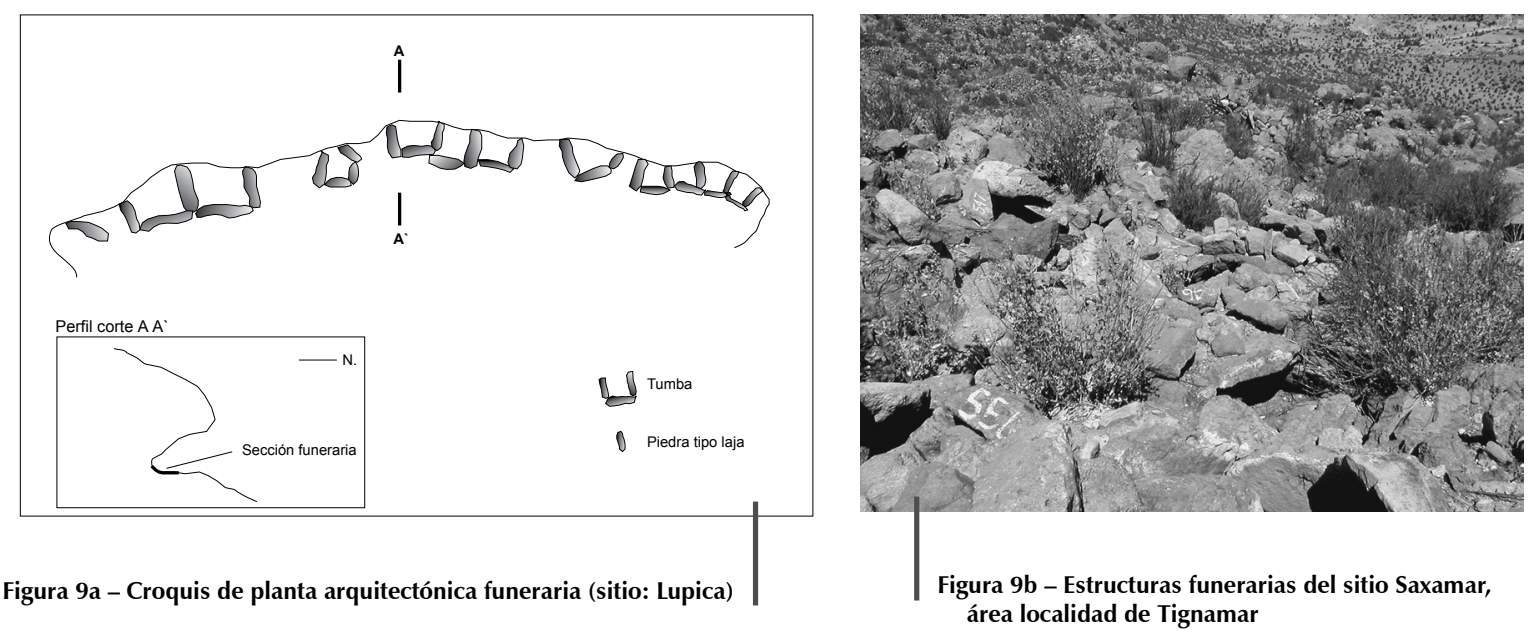

En Saxamar los entierros están en una necrópolis establecida sobre un lomaje rocoso de color gris rosáceo que en verdad es un afloramiento de roca madre que se extiende por la ladera sur del sitio hacia los bajos, rematando en un acantilado. Este sector se ubica en la margen suroeste del sitio.

Las tumbas poseen plantas arquitectónicas de forma circular y oval adosadas unas a otras ocupando toda la superficie regular de este lomaje. Las oquedades naturales fueron aprovechadas como bóvedas funerarias y luego fueron cistadas con bloques de gran tamaño conformando una estructura abovedada de forma semicircular. En otros sectores, sin embargo, como el caso R. 558, el pircado es alto a doble hilada y relleno de grava. Se aprecia que en muchas situaciones se aplicó mortero para consolidar los «adoquines» de los muros. En la preparación de estos morteros, se observan cenizas con fragmentación de cerámica. En anteriores investigaciones, se pudo recuperar desde este sector fragmentación de osamentas humanas, lo cual fue decisivo para determinar un área de cementerio. El estado de conservación de este sector es malo, las cámaras funerarias han sido violentadas con abatimiento de muros por la pendiente, producto de saqueos.

Las edificaciones funerarias, presentes en los tres asentamientos, constituyen en su conjunto sectores de entierro. Se ubicaban en sectores colaterales a las aldeas, se utilizaban espacios naturales con oquedades así como pequeñas cuevas. Da la impresión por la característica del tipo de patrón constructivo que estas tumbas fueron hechas por las poblaciones nativas del valle, no apreciándose incorporaciones de patrones funerarios de la puna como fueron las chullpas de barro. La característica general de las tumbas de los cementerios son cistas agrupadas tipo colmenas.

$\mathrm{Al}$ analizar este tipo de tumba pensamos que estos agricultores serranos tuvieron contacto con las poblaciones de los valles bajos en Arica, especialmente las que se ubican en los sectores medios de los valles de Azapa y Camarones que presentan un tipo de construcción de tumba similar a los de la sierra, sugiriendo una relación que pudo haber alcanzado niveles de parentesco. Otro tipo de vinculación pudo haber sido con gentes Carangas y tal vez Pacajes. Planteamos esta hipótesis por la presencia de cerámica de estilos Chilpe y Tradición Negro sobre Rojo y tumbas cistadas similares a las que aparecen en los poblados del área Circumtiticaca (Heredia, 1993).

Aún no hemos podido determinar el número de entierros. La mayor parte de la información proviene de Lupica donde hemos podido reconocer 5 cráneos pertenecientes a adultos de ambos sexos y algunos huesos diseminados. La presencia de estructuras funerarias, muchas de 
ellas sin restos humanos, sugiere que en estos asentamientos no fue enterrada una población numerosa. Si lo comparamos con las estructuras habitacionales tal vez pudo haber alcanzado un número de 50 personas, información sugerida sobre la base de los hallazgos de chullpas de piedras y cuevas donde fueron depositados los cuerpos sentados con las piernas flexionadas.

\section{DEPÓSITOS}

En cada asentamiento se observan dos tipos de depósitos para guardar la producción, quizás uno haya sido de tipo comunal y otro para guardar la cosecha del Inca. En Huaihuarani el sector de depósitos se ubica en la pared este del mismo cerro que ocupa el sector A, presenta silos bien conservados, construidos en pequeñas cavidades de la roca (fig. 10). Los muros son gruesos, algunos construidos en triple hilada de piedra, utilizándose mortero para consolidar la estructura. Una gruesa capa de tierra fue depositada como sello final. Las bocas de estas estructuras tienden a formas circulares. Otro tipo de estructuras con función de silo, lo constituyen pequeños recintos orientados de norte a sur, construidos a doble hilada de piedras.

En general los pozos de almacenaje aparecen resguardados por la población, a pesar de que se ubicaban en diferentes sectores de los poblados, incluso algunos próximos a corrales. Las evidencias señalan que en estos se guardaban productos agrícolas preferentemente maíz, papas y carnes secas de camélidos.

En Lupica los pozos de almacenaje están conformados por varias estructuras alzadas sobre superficie respondiendo a una planta circular, destinadas para almacenar productos agrícolas y carnes (charqui). Los muros son construidos a doble hilada de piedra en que se empleó cantos rodados como adoquines. Existe empleo de mortero para consolidar el edificio. Finalmente a nivel de superficie, se depositó grava. La estructura tiende a ser abovedada, con nivelación o plomada de los muros en sentido interno de la estructura. El R. 1 es uno de los mejores conservados, su muro sur alcanza una altura aproximada por el exterior de $185 \mathrm{~cm}$.

Podemos cotejar este sector como un complejo económico avecindado con algunas estructuras de encierro de animales para carga y descarga. Otras 11 estructuras, también de almacenaje, están distribuidas por las cotas más bajas de este sector, adosadas varias entre sí, tipificando un ordenamiento orgánico nuclear. El estado de preservación en general es regular a causa del abatimiento de muros. Las evidencias de pozos de almacenaje, sumadas a la presencia de restos de fecas de camelidos en los pisos de los corrales, nos hacen sugerir que estos fueron espacios donde se organizó, a través el intercambio, la economía de las poblaciones serranas. Además no existen estructuras habitacionales complejas para pensar que fue una élite determinada la dueña de la producción. El control de esta estuvo, al parecer, bajo la tutela de la comunidad. Estos espacios prehispánicos más bien se asemejan a lo que hoy en día son las markas, lugares donde la población aymara comercializa o intercambia su producción especialmente por productos traidos de la costa de Arica, incluso son lugares sin mucha complejidad arquitectónica, sino más bien espacios abiertos donde algunas familias permanecen con su ganado que forman parte de las actividades comerciales que se generan.

Los silos en Saxamar están orientados mirando hacia el río, los muros han sido tratados a doble hilada de piedras y presentan cámaras abovedadas construidas sobre superficie. Existen pasillos de movilidad entre ellos (p. ej., R. 669 y R. 666).

Por el abatimiento de muros en muchas estructuras, quedan al descubierto las técnicas constructivas de estos silos. Las bases de los muros están determinadas por el empotramiento de bloques grandes dispuestos horizontal y verticalmente que sirvieron de soportes. Luego, otros bloques menores, puestos sobre los primeros en sentido horizontal, definen la alturas. Existen en este complejo 40 estructuras; detectamos al oeste, en el tramo final del sector $D$, un pircado sin un acabado depurado que sirve como muro madre a algunos silos que se adosan a él por su costado norte y sur (p. ej., R. $691,692,693,694)$. Al concluir su trazado, el muro converge al norte para intersectar y traspasar perpendicularmente a un sendero definido con bloques alineados de este a oeste. Este sendero se viene desplazando por el este, corriendo por la base norte del promontorio principal. 


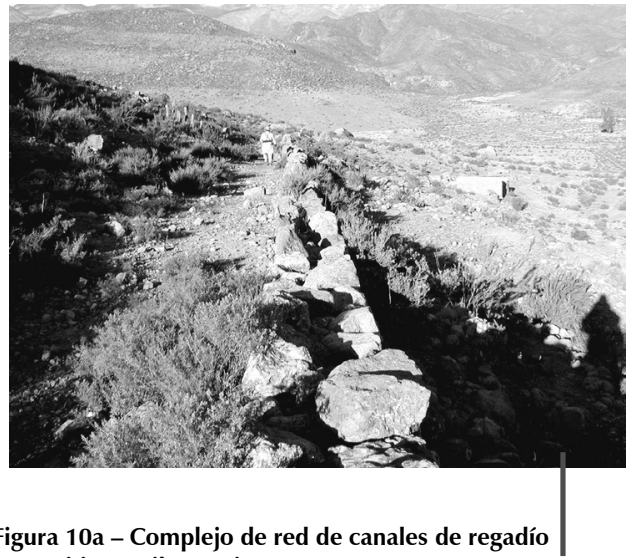
en sitio Huaihuarani

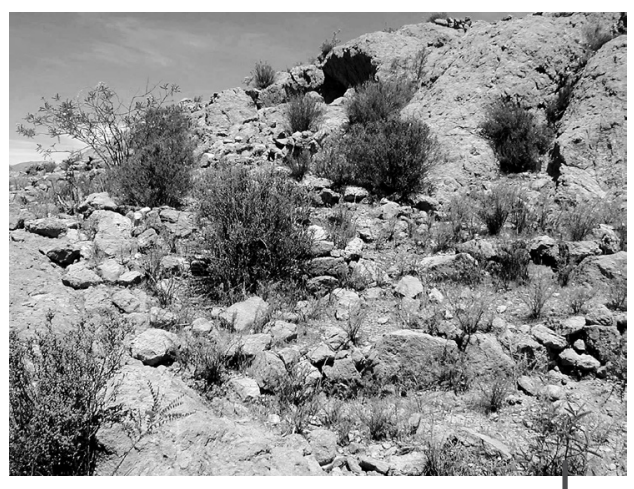

Figura 10c - Terrazas pequeñas y transecto de canal de regadío en sitio Saxamar, sector $E$

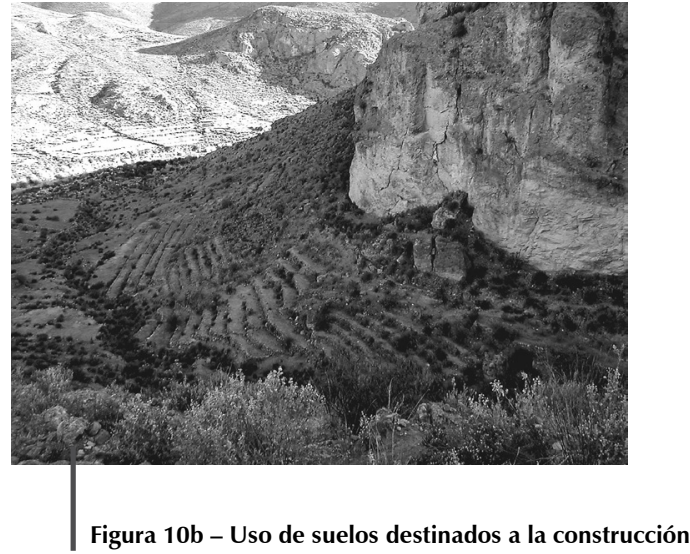
de terrazas de cultivos. Sitio Huaihuarani

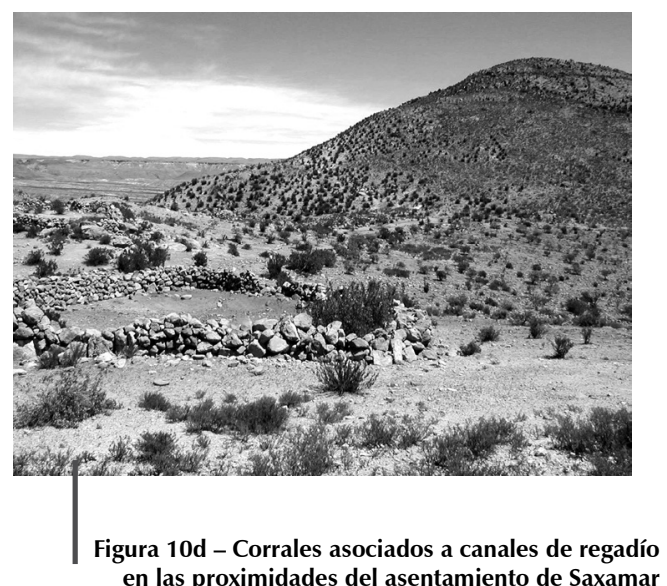
en las proximidades del asentamiento de Saxamar

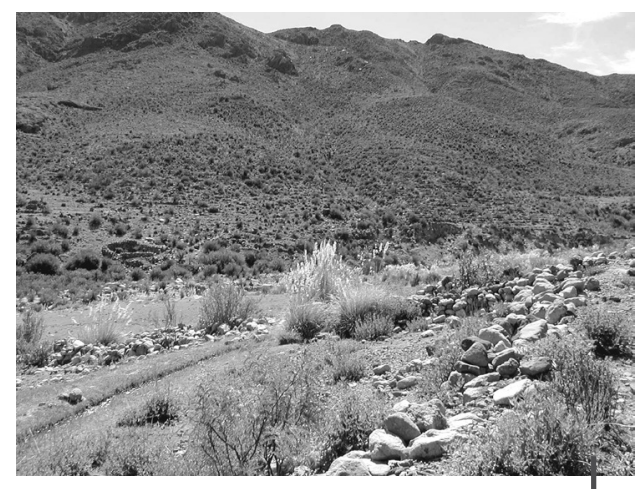

Figura 10e - Canales de regadío prehispanos y actuales en asentamiento serrano de Lupica, sector $\mathbf{G}$ Al fondo, en cotas inferiores del cerro, se observa los delineamientos de picardos atribuidos a terrazas 
En el R. 705 concluye el recorrido del muro madre en dirección a la caja del río Saxamar. En este sector encontramos algunos silos de almacenaje asociados a una piedra de $4 \mathrm{~m}$ de diámetro que presenta fisuras en su cara superior, lo que le da una configuración de «damero», resaltando figuras cuadradas, rectangulares y circulares. Además presenta algunos orificios en el espacio central de la superficie. En los bordes se han desprendido algunos trozos de roca como consecuencia de la erosión natural. No sabemos la función de esta singular estructura granítica, tal vez pudo haber correspondido a una mesa ritual, representando la figura de una chacra.

Aún no hemos podido determinar algunos tipos de recintos en función de productos determinados. Sin embargo, la presencia de algunas mazorcas de maíz y papas chuño encontradas en los estratos de ocupación nos sugiere la posibilidad que fueron estos productos, junto a carnes secas y quinua los que más se depositaron en estos graneros.

\section{CORRALES}

Los corrales se ubican en los faldeos de los cerros, su construcción no presenta técnicas depuradas (fig. 10). En Huaihuarani los espacios que probablemente estuvieron destinados al manejo de animales son de planta rectangular, muy amplios con un cierto depurado en cuanto a la disposición de los bloques. Existe relleno de grava y un acceso al costado sur señalizado por dos jambas en posición vertical.

En Lupica los corrales se caracterizan por espacios de planos inclinados cercanos a la base del mismo valle. Probablemente correspondan a las últimas evidencias habitacionales asociadas a espacios para encierro de animales (corrales). Las estructuras para corrales se desplazan desde el extremo sur hasta la medianía del sector D. Más abajo, un cauce seco algo profundo y de trayectoria norte-sur divide a este sector del valle.

En Saxamar los corrales se hallan ubicados por el sureste del plano bajo el promontorio principal, de superficie sinuosa por elevaciones estrechas que dominan visualmente los valles de Tignamar por el sur y de Saxamar por el norte.

Los recintos 653, 654, 655 y 656 conforman estructuras utilizadas como corrales para supuestas cargas y descargas de animales. Este antecedente se sustentaría por un complejo de estructuras utilizadas como pozos de almacenaje muy próximos a los corrales, construidos a partir del muro oeste del R. 656.

Estos corrales fueron construidos con muros bastante rudimentarios, pero que se han conservado en el tiempo. Se aprecia una técnica mixta en las hiladas que conforman los muros: son de tipo simple y doble aprovechando también en algunos segmentos rocas voluminosas. Los recintos 707, 708, 709 y 710 conforman los espacios destinados a resguardar animales. Están ubicados sobre el plano extenso que va al noroeste. Los muros están construidos en técnica mixta: simple, doble hilada de piedras y rocas de gran volumen; poseen muros medianeros entre sí. Los recintos 714 y 716 que también corresponden a corrales, junto a un silo (R. 715), son las últimas estructuras del sector D. Entre ellos existen claros alterados por afloramientos rocosos de escasa altura. En el caso del R. 714, éste posee acceso con jamba por el este. En el sector D hallamos recintos espaciosos delineados con pircados muy rudimentarios en su manufactura, conservando un patrón irregular desde la perspectiva arquitectónica.

\section{TERRAZAS DE CULTIVOS}

Respecto a la inserción del espacio agrícola en los poblados y su estilo constructivo, desde el punto de vista de la ubicación de los asentamientos estudiados, se desprende que el uso del espacio por estas poblaciones se circunscribió a lugares donde hubo agua permanente (ríos y manantiales) lo cual habría permitido el cultivo de papas y maíz como productos de primer orden, cultivos que han sido identificados en las basuras excavadas. El recurso hídrico utilizado para el riego pudo haber sido producto de la captación de agua de los ríos Belén, Lupica y Ticnamar, 
cuyas aguas son permanentes como consecuencia de los deshielos cordilleranos: además, en estas hoyas hidrográficas hay varias aguadas, que aún son utilizadas por los agricultores serranos para el riego de sus cultivos (fig. 10).

El espacio agrícola relacionado directamente a los poblados se caracteriza por conjuntos de andenerías abandonadas y otras reutilizadas, que corresponden a: Huaihuarani, $11000 \mathrm{~m}^{2}$, Lupica, $22500 \mathrm{~m}^{2}$ y Saxamar, $51000 \mathrm{~m}^{2}$. Los canales principales que utilizaron los pobladores de Huaihuarani, Lupica y Saxamar se desprenden de los ríos: Belén, Lupica y Ticanamar, ubicándose las bocatomas a la altura de los $3600 \mathrm{msnm}$ aproximadamente. En el caso de Saxamar hay un aprovechamiento de la pendiente natural de la topografía serrana para distribuir el recurso agua mediante canales primarios y secundarios en la cota de los $3065 \mathrm{~m}$. Estos andenes fueron construidos con muros de contención de $70 \mathrm{~cm}$ de altura y «banquetas» de $2 \mathrm{~m}$ de ancho, ligeramente inclinadas hacia el borde. Los canales que transportaron el agua tienen muros de contención de hasta 1,50 m de alto y una «banqueta» de $3 \mathrm{~m}$ de ancho con planos rectos y con riego por gravedad. Algunos sectores de terrazas fueron regadas con agua de lluvia, es decir no están conectadas a un canal de regadío lo que sugiere una estrategia de utilización al máximo de los recursos de humedad.

Las terrazas de cultivos indican que sus constructores fueron nativos de los valles de Lupica, Saxamar y Belén, puesto que la cerámica encontrada en dichas terrazas presenta similitudes con las halladas en esos poblados. Por otro lado, el sistema constructivo es similar al ejecutado en todos los valles serranos durante la época prehispánica tardía. Desde el punto de vista de los sistemas agrícolas, constituyen el espacio mayor humanizado en la sierra de Arica y corresponden a sectores con terrazas de cultivos, próximos a los fondos de quebrada o pequeños valles intermontanos. Los espacios aterrazados de uso agrícola se encuentran acompañados de redes de canales y de caminos que comunican las terrazas agrícolas con los poblados de Huaihuarani, Lupica y Saxamar. Un rasgo común a todas las terrazas observadas es el tipo de construcción: un trabajo de cortes horizontales y verticales hechos en las laderas de los cerros y quebradas. Debido a ello los niveles aterrazados están conformados por roca madre en la parte inferior y una débil capa de suelo, en la sección superior. El material de construcción de los muros de contención es roca de origen volcánico obtenida in situ, pues se trata del sustrato que prevalece en la sierra ariqueña. Además, el tipo de roca, por la alta permeabilidad que presenta, favorece el drenaje en los suelos.

En Saxamar las terrazas se ubican a los pies del último promontorio rocoso que define la margen noroeste del sitio y corresponde a terrazas de cultivos distribuidas desde los altos hasta las proximidades del río Saxamar. Las terrazas que ocupan las cotas superiores son pequeñas y estrechas, sus pircados son de hiladas simples de piedra, de baja altura. Se aglomeran en un espacio bastante irregular por las demarcaciones que mantienen los afloramientos de roca. Los espacios de cultivos mayores ocupan las cotas inferiores orientando su distribución también en sentido noreste y suroeste. Cabe hacer notar que la irrigación de las melgas superiores se hacía a través de un canal que corre por la banda norte del sitio, teniendo la bocatoma en la quebrada Quilla Quilla.

Toda esta descripción de cómo construyeron las terrazas y canales nos sugiere un conocimiento cabal del terreno que se refleja en haber subido el agua a niveles altos de las laderas, la utilización de la piedra para evitar el escurrimiento del agua a través de la construcción de canales y una planificada construcción de las terrazas de cultivos.

El agua fue conducida mediante acequias. Para el trabajo de la tierra se usó una azada que estaba constituida por una hoja lítica unida a un mango de madera. Varios de estos ejemplares líticos los hemos hallado en los asentamientos.

Evidentemente toda esta experiencia en el trabajo agrícola implicó una participación de la comunidad en la construcción de estos sistemas agrícolas y en el uso y reparto del agua, lo cual finalmente conllevó a entender una organización del espacio y de la comunidad en el contexto del trabajo de la tierra. 
Si bien es cierto estas terrazas fueron hechas por poblaciones locales, este mismo estilo de construcción de andenería lo encontramos en los valles costeros de Azapa y Camarones, lo que demuestra una vez más que el trabajo agrícola fue una idea que se materializó a lo largo de los valles, participando bajo una misma experiencia tecnológica tanto los grupos costeros serranos de los valles de Arica.

\section{CAMINO Y SENDEROS}

En Huaihuarani constatamos la presencia de restos de un camino flanqueado por soleras que presenta conexión con el área de Laguane (fig. 11). Posee pircados laterales con un ancho promedio de $3 \mathrm{~m}$. Algunos tramos del costado Este han sido finiquitados con un pircado más elaborado dentro del contexto general que es la disposición de rocas alineadas. Frente al sector C, donde se haya el complejo funerario, este camino se abanica en una espaciosa entrada, lo que permite suponer la llegada de pastores con recuas de llamas desde otros centros urbanos provenientes de valles serranos cercano al sector de Belén. Al ingresar a un sector densamente ocupado por recintos habitacionales esta vía queda unida a un recinto por su vértice sureste ( $p$. ej., R.583). Este sector bajo de la ladera este —el camino se conecta a un pircado o alineamiento de rocas - configura circularmente un espacio de superficie de suelo de forma convexa. Es posible que este espacio haya sido utilizado como plaza donde pudo haberse estructurado el intercambio de bienes y productos económicos. Planteamos

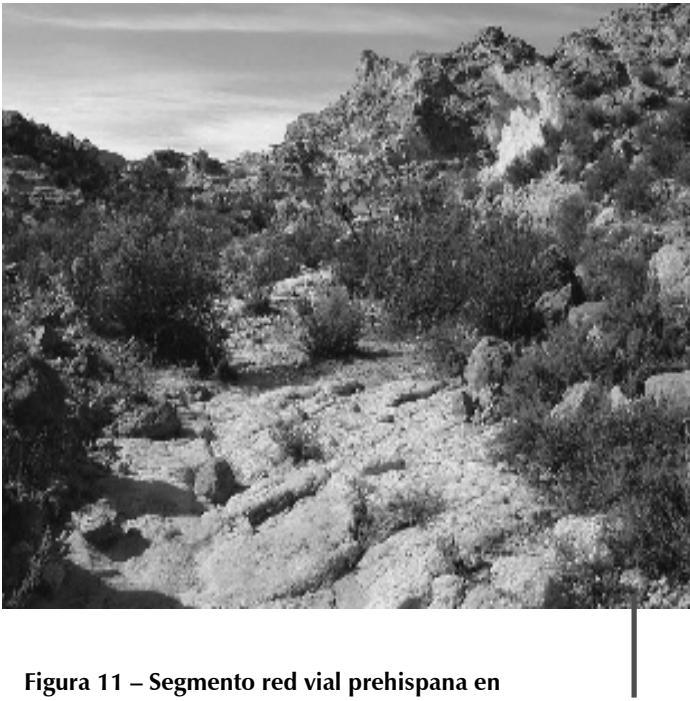

proximidades del sitio Huaihuarani, Belén esta hipotesis puesto que hemos reconocido en este conjunto de evidencias una red de senderos que convergen en puntos neurálgicos de los asentamientos. En estos puntos neurálgicos hemos hallado restos de fecas de camélidos y fragmentación de cerámica, algunas incluso decoradas. Estos espacios se hallan en pendientes suaves o planices, son amplios y divergentes, los cuales les permite tener un dominio estratégico interno. En la actualidad aún podemos observar que en el caso de las comunidades aymaras de la serranía y puna los accesos tienden a converger en espacios amplios donde se da el intercambio.

Esta red vial conocida como Ruta Longitudinal o Precordillerana (Muñoz \& Briones, 1998) corresponde al camino del Inca trazado en la vertiente occidental andina sobre los $3000 \mathrm{msnm}$ (Hyslop, 1992) en la sierra de Arica. Esta está presente según Dauelsberg (1983) en el sector de Belén en varios tramos como Tojo-Tojone, el tramo del poblado de Huaihuarani a Chajpa y Ancopachane; finalmente en la quebrada de Chapiquiña, donde se ubica el pukara de Caillama. Muñoz \& Briones (1998) señalan que esta ruta se desplaza desde el sur del Perú en el sector de Calacota y Matarani cruzando la serranía ariqueña, donde es posible identificarla en primera instancia en el tramo Socoroma-Zapahuira hasta la quebrada de Saxamar. Las irregularidades del terreno precordillerano hizo necesaria una implementación y mantención permanente del trazado, como se observa en el tramo Zapahuira-Pachica.

Otras vías de comunicación son los senderos que cruzan los asentamientos estudiados, estos tienen un ancho promedio de $3 \mathrm{~m}$. Por lo general estas rutas se desplazan por las laderas de cerros y mantienen cierta sinuosidad de acuerdo a la topografía de la zona, cruzan quebradas y se relacionan con el camino troncal de la sierra que está asociado al período Inca (Ruta 
Precordillerana). La presencia de esta red de senderos que cruzaron la sierra demostraría el constante desplazamiento de hombres, bienes y animales durante los períodos Intermedio Tardío y Tardío de la prehistoria y que siguió durante la Colonia. Estos senderos que cruzan la sierra se dirigen hacia la puna y costa; hacia el litoral se desplazan a través de la pampa y otros hacia la quebrada de Livilcar para desembocar en el litoral de Arica. Ambos caminos constituirían las principales redes que comunicarían el valle de Azapa y la costa de Arica con la sierra de Belén y Ticnamar. Por estos caminos suponemos que los caravaneros traficaron pescado, algas, mariscos y en general una variedad de productos marinos, además de frutas, tubérculos, papas y maíz, los cuales ayudaron a sustentar la economía de las poblaciones serranas.

De la misma manera, de la sierra hacia la puna los senderos comunican los poblados altiplánicos de Guallatire, Caquena y Sajama. Es posible que en este tráfico los productos más apetecidos hayan sido el charqui, la lana, la sal, la quinua, los cuales habrían ayudado a complementar la economía de las poblaciones de la sierra.

El análisis de cada uno de los componentes de los asentamientos nos permite plantear similitudes en cuanto a su distribución del espacio; (a) poseen áreas claramente definidas y en algunos casos coexistiendo espacialmente (Ej: habitacional, funeraria y económica), (b) existe una estrecha relación entre silos y corrales, (c) los entierros responden a un patrón colectivo insertos en aleros naturales o chullpas de piedras, (d) el conglomerado habitacional se estructuró en la ladera este, no así en la cima del cerro principal por su escaso espacio de movilidad y bondad del piso, (e) el asentamiento responde a un crecimiento orgánico, aterrazado, con plena armonía respecto de la topografía, (f) como reflejo de una urbe socioeconómica compleja, posee espacio de convergencia ritual, como comunitario, (g) no podemos definir a estos asentamientos como enclaves defensivos ya que debería fundamentarlo la existencia de un muro perimetral, el cual no se constató en una gran extensión, (h) los corrales ocupan espacios sinuosos y planos en el valle, (i) finalmente determinamos que cada uno de estos asentamientos está vinculado uno con otro, gracias a la estructuración de redes viales, que constituyeran el transmisor de tecnología cultural como lo podemos constatar a través de los patrones arquitectónicos, los cuales pueden tener variantes en cuanto a tamaño o densidades de estructuras pero responden a un patrón de forma y construcción similar.

Quizás las diferencias están en tres aspectos específicos. En el poblado de Huaihuarani los muros habitacionales fueron edificados en una hilera de piedras en un mayor porcentaje, en cambio en Lupica las tumbas fueron depositadas en cuevas difiriendo de las construcciones de piedras que se hallan en Saxamar y Huaihuarani. Finalmente en el asentamiento de Saxamar se construyó en la cima del cerro, pero este uso del suelo quizás se deba a la condiciones naturales del área ocupacional. Todas estas diferencias, sin embargo, son de menor grado — de alcance local— si consideramos que los patrones arquitectónicos, indicadores ceramológicos y distribución espacial de los sitios presentan una similitud que se corrobora con los antecedentes cronológicos.

\section{ESPACIO SOCIAL Y POBLACIÓN EN LA SIERRA DE ARICA: COMENTARIOS FINALES}

\section{1. Espacio Social}

La información de los estudios de asentamientos en las alturas de Arica nos lleva al análisis y discusión en torno a ciertos planteamientos teóricos sobre los estudios de asentamiento y áreas de actividad. En primer lugar la importancia de lograr en un medio complejo como lo es el desierto de altura en un espacio habitable, nos lleva a la misma pregunta que años atrás hizo Binford (1988) es decir ¿̇ómo estaban organizadas las actividades humanas en diferentes lugares del planeta? En el caso de las poblaciones de la sierra de Arica, por las condiciones complejas del ambiente — desierto de altura— las actividades humanas se centraron en aprovechar al máximo 
los recursos que el medio les proporcionaba y a organizar los poblados dentro de una compleja red de asentamientos situados estratégicamente conectados a senderos que los comunicaban entre ellos y con los valles costeros del Pacífico y las tierras altiplánicas

En el caso de los poblados de altura el espacio del asentamiento fue armónicamente diseñado, integraron zonas húmedas, que es lo que está en directa relación con la agricultura, manejaron una visibilidad amplia del espacio, dentro de la cual diseñaron las rutas comerciales que los conectaron con la costa y altiplano. En este contexto, la construcción de terrazas y canales de regadío, en cuyas superficies se hallan restos de fragmentos de cerámicas de época precolombina, fueron diseñadas para no romper con la hegemonía del espacio; a su vez las piedras con la cual diseñaron los sistemas de terrazas y canales, no alteran la distribución armónica del paisaje. En este sentido podemos plantear que la construcción de los asentamientos, como lo señalan Criado (1996) y Nielsen (2001), reflejan una compenetración entre el hombre y el medio, no observándose una alteración del paisaje. Los materiales utilizados en la construcción de sus poblados como piedras, maderas, fibras vegetales etc. constituyeron elementos de un eje conformado entre la tierra no construida, la cultivada y la edificada, manifestando por lo tanto una unidad plena ligada a la cosmovisión andina que integró los aspectos politicos, sociales, económicos y ceremoniales.

En segundo lugar el estudio de estos tres asentamientos si bien muestra diferencias en torno a la ubicación de los recintos y la colocación de entierros en cuevas como Lupica, la organización y distribución de los poblados, el estilo arquitectónico y el conjunto ceramológico hallado muestran una relación directa entre los sitios, lo que demostraría una red de asentamientos con áreas de actividad similar; estos asentamientos están en directa relación con la red vial que fue la columna que integró a los distintos poblados serranos de los $3000 \mathrm{msnm}$. De esta manera a partir del sitio arqueológico hemos podido analizar una red cultural, mucho más funcional, que involucró los valles de la sierra de Arica organización que nos recuerda el modelo planteado por Flannery (1976: 5) para el valle de Oaxaca (México), en el cual distingue varios niveles jerarquizados, los cuales configuran un sistema sociocultural a partir del área de actividad, la unidad habitacional, el grupo de residencias alrededor de un patio, el barrio, el sitio arqueológico en su totalidad y la correlación entre diversos sitios de una región. Además como anteriormente lo han discutido Trigger (1990) y Middleton \& Price (1996) en el caso de nuestras investigaciones no solo se ha obtenido una interpretación funcional de un determinado proceso cultural acontecido en un sitio y en un determinado tiempo, sino que hemos registrado procesos de cambio a través de varios cientos de años que involucraron el período Intermedio Tardío (Postiwanaku y las Culturas Regionales) el Inca y el impacto con el europeo.

En tercer lugar al analizar la unidad social (doméstica) si bien no está definida con claridad en los asentamientos, la información de los recintos excavados nos hablan de gente que vivió y ocupó dichas estructuras. Sin embargo, tal como lo plantean Wilk \& Ashmore (1988),

«[...] una unidad social, constituye un grupo de gente que comparte una serie de actividades, como la producción, consumo, recolección de recursos, reproducción, corresidencia y propiedades compartidas. Sobre la unidad doméstica o grupo de residencia señalan que esta puede o no ser reconocida por la gente misma. Pueden vivir en un solo sitio o pueden estar espacialmente dispersos. Los individuos pueden ser miembros de más de una unidad doméstica y es posible que ésta tenga miembros inactivos» (Wilk \& Ashmore, 1988: 6).

De lo anterior resulta complejo determinar arqueológicamente una unidad social en el contexto de las actividades domésticas. Por otro, sabemos a partir del registro etnográfico que una unidad doméstica puede estar dispersa entre varias residencias y que varias unidades domésticas pueden compartir una sencilla residencia (Wilk \& Ashmore, 1988: 6).

Al analizar los conjuntos habitacionales observamos que estos se caracterizan por un patrón de recinto de forma circular y oval la que se visualiza como una generalidad para los poblados estudiados. En estos asentamientos se desarrollaron diferentes actividades de la vida cotidiana como las actividades domésticas (viviendas), económicas (silos y corrales) y mortuorias (entierros). 
De acuerdo con la extensión alcanzada por los asentamientos en lo que se refiere al espacio doméstico y funerario, Huaihuarani abarcó $60000 \mathrm{~m}^{2}$, siendo su cota más alta $3100 \mathrm{msnm}$. Saxamar, a su vez, abarcó $70000 \mathrm{~m}^{2}$, teniendo su cota más alta en $3130 \mathrm{msnm}$. Finalmente Lupica abarcó $60000 \mathrm{~m}^{2}$, constituyéndose su cota más alta en 3000 msnm.

Respecto al espacio interior en las viviendas, las evidencias señalan que este alcanzaró dimensiones de $5 \mathrm{~m} \times 3 \mathrm{~m}$ y $4 \mathrm{~m} \times 2 \mathrm{~m}$ con una sola entrada. Este fue acondicionado para albergar al núcleo familiar especialmente en la noche donde alrededor de un fogón pudieron comunicarse. $\mathrm{Si}$ bien las basuras son escasas se desprende que en su interior comieron, pernoctaron y molieron alimentos; la presencia de batanes con sus respectivas manos de moler son indicadores de esta actividad dentro y fuera de los recintos habitacionales, quizás con una leve tendencia de moler fuera de los recintos como se observa en el sitio Huaihuarani (66\%) (ver fig. 12). Da la impresión que al interior de los recintos, el espacio familiar estuvo organizado a partir de un espacio o punto central, el fogón, que al parecer constituyó el centro térmico. Una muestra aleatoria tomada de 12 recintos habitacionales en cada uno de los asentamientos nos entregó un promedio de 4 a 5 fogones por recinto (ver fig. 13).

La entrada a los recintos, y en algunos casos la división interior que edificaron, permiten sugerir una actividad doméstica vinculada con las últimas horas del día y con el descanso. Pensamos que gran parte de la vida cotidiana se hizo en el valle, especialmente en las terrazas agrícolas donde se concentró el trabajo familiar y posiblemente en los espacios de mayor interacción social como pudieron haber sido las plazas y corrales. Es posible pensar que por la gran cantidad de estructuras los grupos de familias hayan ocupado más de algún recinto, ya sea en forma contemporánea o en períodos distintos. Recintos pareados constructivamente muy similares y cerámica de igual manufactura apoyarían esta hipótesis. Este tipo de información es fundamental, pues nos permiten inferir los patrones de comportamiento del grupo social a partir de
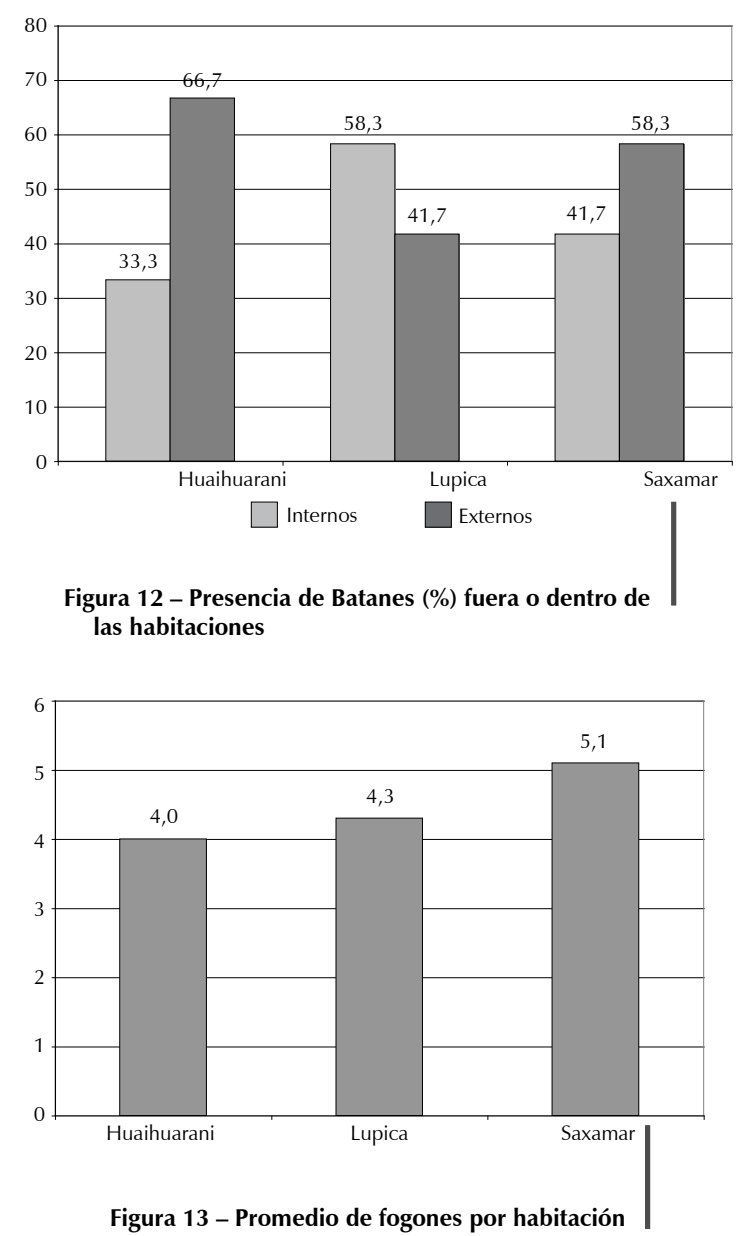

Sitios: Huaihuarani, Lupica y Saxamar

la distribución espacial que presenta el registro arqueológico. A diferencia de lo que plantean López \& Molina (1986: 259) en el sentido que el análisis de la complejidad de una unidad doméstica (o un conjunto de ellas) permite vislumbrar el grado de desarrollo y estratificación de la sociedad a la cual pertenece, en el caso de las estructuras habitacionales de la sierra de Arica, el patrón es conservador presentando similitudes en relación al tipo de recinto.

Dentro de la estructura global de las aldeas los sectores que la definen están claramente organizados a pesar que a simple vista aparece un conjunto de estructuras muy atomizadas. Cada espacio cumple su función y mantiene una estrecha relación con el medio que nos circunda. Así la aldea constituye el espacio mayor, algo así como el macrocosmo. Al parecer fue en ella 
donde se dio y determinó la vida cotidiana. Quizás los recintos de mayor envergadura fueron las plazas donde socializó (concentró e interactuó) la población, allí intercambiaron productos y se establecieron fuertes relaciones sociales. Para delimitar estas plazas buscaron lugares abiertos, en especial planices permitiendo una mayor concentración y circulación de individuos. Por otro lado, los recintos menores al parecer fueron espacios donde albergaron en la noche, lo cual hizo que prendieran fuego y prepararan alimentos.

En síntesis las aldeas, a través del conjunto de áreas que la conformaban en la que se incluye las áreas agrícolas y los espacios donde pastaron y albergaron sus recuas de animales, formaron el circulo mayor base de la interacción comunal y familiar, a diferencia de los recintos que constituyeron espacios temporales en la vida de los agricultores serranos. Esto nos hace pensar en la perspectiva del espacio global que el espíritu de la comunidad estuvo dado en la aldea en la cual reflejaron su imagen y tradiciones.

Rapaport (1972) plantea antecedentes etnográficos que nos ayudan a entender este sistema al señalar que en el caso de las culturas indígenas «la aglomeración de las casas como un conjunto fue considerada como un cuadro de vida, la casa es simplemente una parte de este dominio más íntimo, más cerrado y más resguardado». Este concepto es posible analizarlo a través de los símbolos. Al respecto Caiuby Novaes et al. (1983) señalan que los niños de las comunidades amazónicas como los bororo, xavantes, warzana, xinguanos, etc. jamás dibujan una casa aislada, sino un conjunto de ellas formando una aldea.

En cuarto lugar respecto a las áreas de actividad observamos una sectorización de éstas en los distintos poblados; presentan algunas de ellas similitud en cuanto a las características funcionales planteadas por Manzanilla (1986: 11-13), es decir áreas de producción, uso o consumo, almacenamiento y evacuación. Sin embargo, en el caso de la sierra de Arica, éstas se dieron al parecer en espacios de mayor convergencia social tales como la chacra, plazas o estructuras comunales como las kallankas durante el período Inca. En los recintos habitacionales no se observan áreas de actividad especializadas al parecer el tiempo que los individuos permanecieron en ellos fue reducido aún cuando estos recintos cumplieron su función de espacios de alimentación y refugio. En cuanto a las áreas de almacenamiento, éstas fueron construidas en sectores determinados de los asentamientos vinculados a los corrales.

El análisis del espacio habitacional permite inferir que los pobladores que ocuparon dichos asentamientos fue gente que aprovechó las características topográficas del terreno planificando los poblados bajo un sistema de autodefensa que es común en los sitios de la sierra durante los períodos Intermedio Tardío y Tardío. Éste habría sido construido entre otras razones como consecuencia de conflictos interétnicos, los que se produjeron tal vez por intereses del uso del agua y espacios agrícolas. Algunas referencias dadas a conocer por Vasquez de Espinosa (1948 [1618]) nos hablan de la tensión que provocaba el uso del agua para el riego en las poblaciones del sector alto del valle de Azapa, como Humagata, especialmente en períodos de escasez del recurso hídrico. De acuerdo a lo planteado por Ruiz \& Albeck (1997) estos asentamientos están dentro de la categoría de pukara que corresponderían a asentamientos elevados naturalmente protegidos y de acceso dificultoso, con gran visibilidad de su entorno. Sin embargo, tenemos que dejar establecido que no hay extensos muros defensivos. Sus emplazamientos están cercanos a caminos o vías de circulación, algunas de ellas construidas en época preinca incluso anterior a ésta (Muñoz \& Briones, 1998).

\section{LA POBLACIÓN}

Si consideramos que la cerámica a través de los estilos decorativos pudo haber sido un indicador de etnicidad existiría una alfarería que caracterizaría un estilo local propio de los valles costeros como fueron: San Miguel, Pocoma y Gentilar que definirían la Cultura Arica. Otro estilo lo constituiría Charcollo que estaría vinculado a una población local de naturaleza serrana, propia de los valles altos de Arica (Romero, 2003). Otros estilos de aparente origen altiplánico 
circumtiticaca lo conforma la tradición Negro sobre Rojo representado por el estilo Chilpe y en el caso particular de Lupica el estilo Tumilaca, lo cual confirmaría la presencia de poblaciones vinculadas al epílogo de Tiwanaku. Estos tipos decorativos expresan claramente una interacción de estilos de orígenes distintos, uno costero-valluno y otro serrano-altiplánico, esta situación podría traducirse en una presencia de dos tradiciones culturales interactuando en un espacio como la sierra ariqueña que articuló ambas tradiciones.

La población nativa de estos valles serranos manufacturó la alfarería no decorada, especialmente de uso doméstico, como las que presentan pastas tipo, 103, 104 y 105 preferentemente de color grises, rosaseas y cafesosas con formas de ollas y jarras principalmente (Santos, 1998). Sus semejanzas con los tipos manufacturados en la costa nos sugieren una tradición más local elaboradas por las poblaciones de los valles costeros tal vez perteneciente a la Cultura Arica. Esta interacción habría perdurado por varios cientos de años, aunque los fechados logrados para los estilos mencionados son más bien tardíos: 1476 d. C. promedio para Huaihuarani, 1468 d. C. promedio para Saxamar y 1522 d. C. promedio para Lupica. A pesar de estas fechas sugerimos que la emergencia de estos poblados y la interacción que se produjo en ellos, los sitúa a partir de 1300 d. C., perdurando hasta el período de contacto indígena-europeo.

Desde el punto de vista de la población, las osamentas, fundamentalmente cráneos hallados en Lupica constituyen junto a las osamentas de Incauta, Codpa (Aufderheide, 1987) las únicas evidencias de naturaleza física estudiadas y que se asocian a gente prehispánica de origen serrano. Estos hallazgos comprueban la existencia de una población que vivió y fue enterrada en dichos poblados, a pesar de abandonos producidos por situaciones de escasez de alimentos o de enfrentamiento.

\section{Referencias citadas}

ALBARRACIN, J \& MATHEWS, J. E., 1990 - Asentamientos Prehispánicos del valle de Tiwanaku, vol. 1; Bolivia, La Paz.

ALDENDERFER, M., 1990 - Cronología y Definición de las fases Arcaicas en Asana, Sur del Perú. Chungará, 24-25: 13-35.

AUDERHEIDE, A., 1987 - Restos humanos del Pukará de Incauta. El poblamiento prehispánico tardío en el valle de Codpa. Una aproximación a la historia regional (Muñoz, Chacama \& Espinosa). Chungará, 19: 7-70; Arica.

BERMANN, M. \& GRAFFMAN, G., 1989 - Arqueología de Lukurmata. In: La tecnología y organización de la producción agrícola en el Estado de Tiwanaku (Kolata A., ed.) 2 (7): 153-172.

BINFORD, L., 1988 - En busca del pasado; España, Barcelona: Crítica. Arqueología.

CAIUBY, S., LADEIRA, A. M., DA SILVA, L., VIDAL, C., GALLOIS, S. D. \& HUSSAK, L., 1983 Habitacoes Indígenas. Nobel editora de Universidades de San Paulo.

CRIADO, F., 1996 - La arqueología del paisaje como programa de gestión integral del Patrimonio Arqueológico. PH Boletín, 14: 15-19; España.

DAUELSBERG, P., 1983 - Investigaciones arqueológicas en la sierra de Arica. Chungará, 11: 63-84; Arica.

FLANNERY, K., 1976 - The Early Mesoamérica Village; New York: Academic. Press.

GOLDSTEIN, P., 1989 - OMO, A Tiwanaku Provincial Center un Moquegua, Perú. Unpublished Ph. D. Dissertation Department of Anthropology. The University of Chicago.

GORDILLO, J., 1996 - Desarrollo Regional Tardío y ocupación Inca en la Pre-Cordillera de Tacna. Ciencia y Desarrollo, 3: 96-111; Tacna. 
HEREDIA, M., 1993 - Las torres funerarias de Kullikulli. Pumpunku, 2 (5-6): 162- 171.

HYSLOP, J., 1992 - Qhapaqñan: El sistema vial incaico, 268 p.; Lima: Instituto Andino de Estudios arqueológicos.

JANUSEK, J., 2001 - Diversidad Residencial y el Surgimiento de la Complejidad en Tiwanaku. Boletín de Arqueología PUCP, 5: 251- 294; Lima.

KENT, S., 1990 - Activity areas and architecture: An interdisciplinary view of the relationship between use of space and domestic built en viroments. In: Domestic architecture and the use of space: an interdisciplinary cross-cultural study (Kent, S., ed.): 1-8; Cambridge: Cambridge University Press.

KOLATA, A., 1989 - Arqueología de Lukurmata. In: La tecnología y organización de la producción agrícola en el estado de Tiwanaku (Kolata. A., ed.) 2 (1): 13-40.

LÓPEZ, D., \& MOLINA, D., 1986 - Unidades habitacionales Prehispánicas de Puebla y Tlaxcala. In: Unidades habitacionales Mesoamericanas y sus áreas de actividad (Manzanilla, L., ed.); México, D. F.: IIA/UNAM.

MANZANILLA, L., 1986 - Unidades habitacionales Mesoamericanas y sus áreas de actividad. In: Unidades habitacionales Mesoamericanas y sus áreas de actividad; México D. F.: IIA/ UNAM.

MIDDLETON, W. \& PRICE, D., 1996 - Identification of activity areas by multi-element chacarterization of sediments from modern and archaeological house floors using inductively coupled plasma-atomic emission spectroscopy. Journal of Archaeological. Science, 23: 1-15.

MUÑOZ, I., 2004 - Estrategias de organización prehispánicas en el valle de Azapa: el impacto de la agricultura en un valle del desierto costero; Chile, Arica: ediciones Universidad de Tarapacá.

MUÑOZ, I., 2005 - Ocupación del espacio doméstico y áreas de actividad generadas en el asentamiento prehispánico de San Lorenzo. Dialogo Andino, volumen en edición.

MUÑOZ, I., \& BRIONES, L., 1998 - Poblados, rutas y arte rupestre precolombinos de Arica: descripción y análisis de sistema de organización. Chungará, 28 (1-2): 47-84; Arica.

MUÑOZ, I., CHACAMA, J., \& SANTOS, M., 1997 - Tambos, pukaras y aldeas, evidencias del poblamiento humano y de contacto indígena-europeo en el extremo norte de Chile: análisis de los patrones de habitacionales y nuevas dataciones radiométricas. Diálogo Andino, 16: 123-190; Arica.

NIELSEN, A., 2001 - Evolución del espacio doméstico en el norte de Lipez (Potosí, Bolivia). Ca. 900-1700 d. C. Estudios Atacameños, 21: 41-62; San Pedro de Atacama.

NIELSEN, A. \& RIVOLTA, M. C., 1997 - Asentamientos residenciales de ocupación breve en la quebrada de Humahuaca (Jujuy, Argentina). Chungará, 29 (1): 19-33; Arica.

NIEMEYER, H. \& SCHIAPPACASSE, V., 1981 - Aportes al conocimiento del periodo tardío del extremo norte de Chile: análisis del sector Huancarane del valle de Camarones. Chungará, 7: 3-104; Arica.

NIEMEYER, H., SCHIAPPACASSE, V., \& SOLIMANO, I., 1971 - Patrones de poblamiento en la quebrada de Camarones. In: Actas del VI Congreso Nacional de Arqueología Chilena: 115-138; Santiago.

NÚNEZ, L., 1982 - Temprana emergencia del sedentarismo en el desierto chileno: Proyecto Caserones. Chungará, 9: 80-123; Arica.

RAPOPORT, A., 1972 - Pour une anthropologie de la maison, xiv + 209 p.; Paris: Dunod.

RAPPAPORT, L., 1990 - Systems of activities and systems of settings. In: Domestic architecture and the use of space: an interdisciplinary cross-cultural study, (Kent, S., ed.): 9-20; Cambridge: Cambridge University Press.

RIVERA, M., SHEA, D., CAREVIC, A., \& GRAFFAM, G., 1995-1996 - En torno a los orígenes de las sociedades complejas andinas: Excavaciones en Ramaditas, una aldea formativa en el desierto de Atacama, Chile. Diálogo Andino 14-15: 205-240; Arica. 
ROMERO, A., 1999 - Ocupación multiétnica en la sierra de Arica: arquitectura, uso del espacio y distribución cerámica en el poblado arqueológico de Huaihuarani. Boletín Zeta. www. Masma.Uta.cl.

ROMERO, A., 2003 - Chullpas de barro, interacción y dinámica política en la precordillera de Arica durante el periodo Intermedio tardío. Textos antropológicos, 14 (2): 83-104; La Paz, Bolivia.

RUIZ, M. \& ALBECK, M., 1997 - El fenómeno pukara visto desde la puna Juneña. Cuadernos, 9: 233-256; Jujuy.

SANTORO, C., 1995 - Late prehistoric regional interaction and social change in a coastal valley of northern Chile, 381 p. Doctoral Dissertation, University of Pittsburgh.

SANTORO, C., HIDALGO, J. \& OSORIO, A., 1987 - El estado Inca y los grupos étnicos en el sistema de riego de Socoroma. Chungará, 19: 71-92; Chile, Arica.

SANTOS, M., 1998 - Análisis tipológico de la cerámica de la sierra de Arica; Arica. Segundo informe FONDECYT 1950980.

STANISH, CH., 1989 - Arqueología de Lukurmata. In: La tecnología y organización de la producción agrícola en el estado de Tiwanaku (Kolata, A., ed.), 2 (3): 41-57.

STANISH, CH., 1990 - Complementariedad zonal en Moquegua. Una aproximación desde el valle de Otora. Gaceta Arqueológica Andina, V (18-19): 137-157.

SCHIAPPACASSE, V. \& NIEMEYER, H., 1998 - Continuidad y cambio cultural en el poblado actual colonial e Inca de Pachica, Quebrada de Camarones. Chungará, 29 (2): 209-248; Arica.

TRIGGER, B., 1990 - A history of archaeological thought; Cambridge: Cambridge University Press.

VÁSQUEZ DE ESPINOSA, A., 1948 [1618] - Compendio y descripción de las Indias Occidentales; Washington: Smithsonian Institution.

WILK, R. \& ASHMORE, W., 1988 (eds.) - Household and community in the Mesoamerican Past; Albuquerque: University of New Mexico Press.

WILLIAMS, P., ISLA, J. \& NASH, D. J., 2001 - Cerro Baul: Un enclave Wari en Interacción con Tiwanaku. Boletín de Arqueología PUCP, 5: 69-87; Lima. 